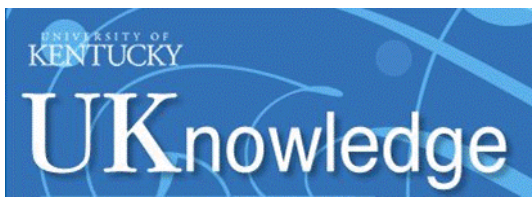

University of Kentucky

UKnowledge

Sanders-Brown Center on Aging Faculty

Publications

Aging

$9-2015$

\title{
Novel Human ABCC9/SUR2 Brain-Expressed Transcripts and an eQTL Relevant to Hippocampal Sclerosis of Aging
}

Peter T. Nelson

University of Kentucky, pnels2@email.uky.edu

Wang-Xia Wang

University of Kentucky,wwangc@uky.edu

Bernard R. Wilfred

University of Kentucky, bernard.wilfred@uky.edu

Angela Wei

University of Kentucky, angela.wei@uky.edu

James Dimayuga

University of Kentucky, james.stephen@uky.edu

See next page for additional authors

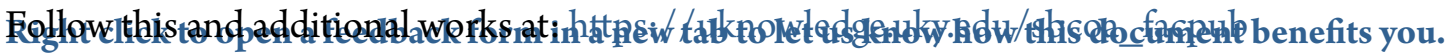

Part of the Biostatistics Commons, Geriatrics Commons, Medical Pathology Commons, and the Neurosciences Commons

\section{Repository Citation}

Nelson, Peter T.; Wang, Wang-Xia; Wilfred, Bernard R.; Wei, Angela; Dimayuga, James; Huang, Qingwei; Ighodaro, Eseosa T.; Artiushin, Sergey C.; and Fardo, David W., "Novel Human ABCC9/SUR2 Brain-Expressed Transcripts and an eQTL Relevant to Hippocampal Sclerosis of Aging" (2015). Sanders-Brown Center on Aging Faculty Publications. 94.

https://uknowledge.uky.edu/sbcoa_facpub/94 


\section{Authors}

Peter T. Nelson, Wang-Xia Wang, Bernard R. Wilfred, Angela Wei, James Dimayuga, Qingwei Huang, Eseosa T. Ighodaro, Sergey C. Artiushin, and David W. Fardo

Novel Human $A B C C 9 / S U R 2$ Brain-Expressed Transcripts and an eQTL Relevant to Hippocampal Sclerosis of Aging

\section{Notes/Citation Information}

Published in Journal of Neurochemistry, v. 134, issue 6, p. 1026-1039.

(C) 2015 International Society for Neurochemistry

The copyright holder has granted the permission for posting the article here.

The document available for download is the authors' post-peer-review final draft of the article.

Digital Object Identifier (DOI)

https://doi.org/10.1111/jnc. 13202 


\title{
Novel human $A B C C 9 / S U R 2$ brain-expressed transcripts and an eQTL relevant to hippocampal sclerosis of aging
}

\author{
Peter T. Nelson ${ }^{*}, \neq, 1$, Wang-Xia Wang ${ }^{*}, 1$, Bernard R. Wilfred ${ }^{*}$, Angela Wei $^{*}$, James \\ Dimayuga*, Qingwei Huang ${ }^{*}$, Eseosa Ighodaro ${ }^{*}$, Sergey Artiushin ${ }^{*}$, and David W. Fardo ${ }^{\star}, \dagger$ \\ "Sanders-Brown Center on Aging, University of Kentucky, Lexington, Kentucky, USA \\ tDepartment of Biostatistics, University of Kentucky, Lexington, Kentucky, USA \\ ¥Department of Pathology, University of Kentucky, Lexington, Kentucky, USA
}

\begin{abstract}
$A B C C 9$ genetic polymorphisms are associated with increased risk for various human diseases including hippocampal sclerosis of aging. The main goals of this study were $1>$ to detect the $A B C C 9$ variants and define the specific $3^{\prime}$ untranslated region ( $3^{\prime}$ UTR) for each variant in human brain, and $2>$ to determine whether a polymorphism (rs704180) associated with risk for hippocampal sclerosis of aging pathology is also associated with variation in $A B C C 9$ transcript expression and/or splicing. Rapid amplification of $A B C C 9$ cDNA ends ( 3 'RACE) provided evidence of novel $3^{\prime}$ UTR portions of $A B C C 9$ in human brain. In silico and experimental studies were performed focusing on the single nucleotide polymorphism, rs704180. Analyses from multiple databases, focusing on rs704180 only, indicated that this risk allele is a local expression quantitative trait locus (eQTL). Analyses of RNA from human brains showed increased ABCC 9 transcript levels in individuals with the risk genotype, corresponding with enrichment for a shorter $3^{\prime}$ UTR which may be more stable than variants with the longer $3^{\prime}$ UTR. MicroRNA transfection experiments yielded results compatible with the hypothesis that miR-30c causes down-regulation of SUR2 transcripts with the longer 3' UTR. Thus we report evidence of complex ABCC9 genetic regulation in brain, which may be of direct relevance to human disease.
\end{abstract}

\section{Keywords}

KATP; SUR2A; SUR2Ab; SUR2B; TDP-43

\footnotetext{
Address correspondence and reprint requests to Peter T. Nelson, Department of Pathology, Division of Neuropathology, Rm 311, Sanders-Brown Center on Aging, 800 S. Limestone Avenue, University of Kentucky, Lexington, KY 40536-0230, USA. pnels2@email.uky.edu.

${ }^{1}$ The authors wish it to be known that, in their opinion, the first two authors should be regarded as joint First Authors.

Conflict of interest disclosure

The authors have no conflicts of interest to report.

Supporting information

Additional supporting information may be found in the online version of this article at the publisher's web-site:

Figure S1. Transcript-specific primers enables PCR to test for the presence of $S U R 2 A$ transcripts with the novel $S U R 2 A$-specific 3’UTR portion in human tissues.

Figure S2. RT-PCR was performed using additional transcript-specific primers (arrows indicate locations) to test for the presence of $S U R 2 A$, SUR2B, and SUR2Ab transcripts including the novel SUR2A-specific 3'UTR portion in human tissues.

Figure S3. Correlations between qPCR results from the four primer pairs shown in Fig. 9.

Table S1. PCR primers used in this study.
} 
The human ATP-binding cassette, subfamily $\mathrm{C}$, member 9 (ABCC9) gene encodes a polypeptide known as sulfonylurea receptor 2 (SUR2); here we employ established terminology referring to the $A B C C 9$ gene, whereas $S U R 2$ mRNA and SUR2 protein are products of the same gene (Shi et al. 2012Nichols et al. 2013). ABCC9/SUR2 is expressed in many human tissues, is relevant to human diseases, and is a targe of therapeutic strategies (Zhang et al. 2010; Shi et al. 2012 Allebrandt et al. 2013; Czeschik et al. 2013; Nichols et al 2013; Nelson et al. 2014). However, much remains to be learned about this intriguing gene, and, in particular, little is known about $A B C C$ 9/SUR2 neurochemistry in the human brain. Here, we focused on characterizing human brain $S U R 2$ transcripts and determining whether a previously described gene variant linked to human disease is a local expression quantitative trait locus (eQTL), i.e., whether the gene variant is associated with altered gene expression.

Understanding SUR2 in the human brain is made challenging by multiple levels of biologic complexity. SUR2 is a large (up to 1509 amino acids), evolutionarily conserved protein with multiple membrane-spanning domains. ABCC 9 gene products (SUR2 transcript and/or SUR2 protein) are expressed robustly in vascular tissue - smooth muscle, pericytes, and endothelium - and also in neurons, astrocytes, oligodendrocytes, microglia, macrophages, and many other cells and tissues (see e.g., Lee et al. 1998; Zawar et al. 1999; Pelletier et al. 2000; Lacza et al. 2003; Bondjers et al. 2006; Ploug et al. 2010; Zhou et al. 2012). As SUR2 cellular- and tissue-level functions may also diverge across species, an 'experimental window' to elucidate the gene's role in a human disease is difficult to achieve. Despite the challenges, multiple studies have found that SUR2 plays important roles in regulating vascular tone and in cellular responses to stress including to hypoxia and ischemia (Chutkow et al. 2002; Seino and Miki 2003; Elrod et al. 2008; Flagg et al. 2010; Nichols et al. 2013). Two additional key themes have emerged from human studies: first, $A B C C 9$ gene mutations and polymorphisms are linked to multiple human diseases; and second, SUR2 mRNA splicing is tissue-specific and functionally important.

$A B C C 9$ genetic polymorphisms are associated with risk for diverse human diseases. Stop codon mutations in $A B C C 9$ lead to a condition called hypertrichotic osteochondrodysplasia, or 'Cantu syndrome' (van Bon et al. 2012; Harakalova et al. 2012). Exonic ABCC9 single nucleotide polymorphisms (SNPs) have been linked to risk for atrial fibrillation, dilated cardiomyopathy, and myocardial infarction (Bienengraeber et al. 2004; Nichols et al. 2013; Smith et al. 2013). In contrast, intronic SNPs that cluster in the $3^{\prime}$ portion of ABCC9 have been associated with risk for human brain illnesses, including sleep problems, depression, and hippocampal sclerosis of Aging (HS-Aging) (Allebrandt et al. 2013; Parsons et al. 2013; Nelson et al. 2014).

HS-Aging is a prevalent neurodegenerative disease and the present authors identified a particular SNP (rs704180) that is associated with HS-Aging risk (Nelson et al. 2014); this finding was replicated subsequently in a separate study sample (Nelson et al. 2015). We also found evidence to support the hypothesis that HS-Aging is a 'brain-wide' disease, rather than only affecting the medial temporal lobe structures such as the hippocampal formation (Neltner et al. 2014). Unfortunately, detailed analyses of SUR2 regulation in human brain 
have not been published previously. Nor has there been a prior report to describe whether, and how, the pathogenic intronic gene variants are associated with altered SUR2 genetic regulation.

RNA splicing that produces alternative SUR2 mRNA transcripts is a conspicuous feature of $A B C C 9$ regulation, with multiple alternatively spliced exons in the $3^{\prime}$ portion of the gene (Chutkow et al. 1999; Shi et al. 2005; Ye et al. 2009). Two main splice variants have been described: SUR2A and SUR2B. These transcripts are generated through differential splicing of two $A B C C 9$ exons (referred to here as Exon38 and Exon39) which encode the polypeptides' carboxy terminal portions (Chutkow et al. 1996; Inagaki et al. 1996; Isomoto et al. 1996; Davis-Taber et al. 2000). SUR2A has relatively high expression in cardiac and skeletal muscle cells, whereas $S U R 2 B$ has more widespread expression including in the brain (Chutkow et al. 1996; Isomoto et al. 1996; Davis-Taber et al. 2000; Shi et al. 2005; Ploug et al. 2010). Some other single exons in the gene have been described to be alternatively spliced. For example, a rare non-conventional splicing event skips 25 internal exons to produce a short variant expressed in mitochondria with a new splice junction at exons 4 and 29 of the annotated gene (Ye et al. 2009).

Thus guided by both human disease relevance and RNA splicing activity in $A B C C 9$, we focused on the $3^{\prime}$ portion of the gene in the current study. The main goals were to improve characterization of brain-expressed SUR 2 transcripts, and to test whether a genetic polymorphism associated with human brain disease is associated with altered gene expression. We found human brain $S U R 2$ transcript variants that previously were not annotated, indicating novel alternative splicing in the mRNAs' coding region and also $3^{\prime}$ untranslated region ( $3^{\prime} \mathrm{UTR}$ ) variants. Evidence gathered from multiple sources supports the hypothesis that a gene variant, associated with HS-Aging pathology, is also an eQTL that influences the levels and splice variants of brain mRNA transcripts derived from $A B C C$.

\section{Methods}

\section{In silico studies}

To evaluate evidence for association between rs704180 status and $A B C C 9$ expression, analyses were performed using web servers designed to evaluate eQTLs; thus we used data in the public domain to compare transcript levels between persons with and without the HSAging risk genotype. Information about the databases and web servers used in the current study is presented in Table 1. The following web servers were queried: SNPExp (Holm et al. 2010), which includes DNA and SNP data from lymphoblastoid cells transformed with human DNA; GTEx (The GTEx Consortium 2013; Moore 2013), and here we used the human brain tissue for which there was the largest sample size ( $n=34$ samples from the basal ganglia); and BRAI-NEAC (Ramasamy et al. 2014), which evaluates brain tissue samples from ten different areas isolated from 133 different human subjects. For additional information and acknowledgment regarding public access web servers, please see Supporting Information. The study was performed in accordance with the local (University of Kentucky) IRB and all patients signed informed consent for brain autopsy and research to be performed on their brain tissues. 


\section{Total RNA and mRNA isolation}

Cases used for isolation of human tissue are described below and in Table 2. Non-brain tissues, and the isolation of total RNA with Trizol LS, were performed as described previously (Wang et al. 2014, 2015). Poly-A mRNA isolation used an affinity oligo dT matrix (Oligo (dT) 25 cellulose beads; New England Biolabs) isolation method following manufacturer's instructions with minor modifications. Briefly, $0.5-1 \mathrm{mg}$ of total RNA isolated from hippocampus or skeletal muscle was dissolved in $0.5 \mathrm{~mL}$ loading buffer $(0.5$ $\mathrm{M} \mathrm{NaCl}, 20 \mathrm{mM}$ Tris- $\mathrm{HCl}, \mathrm{pH} 7.5,1 \mathrm{mM}$ EDTA) and heated to $65^{\circ} \mathrm{C}$ for $5 \mathrm{~min}$. RNA samples were quickly cooled down in ice for $5 \mathrm{~min}$ before incubated with $12.5 \mathrm{mg}$ of Oligo $(\mathrm{dT})_{25}$ cellulose beads. Incubation was performed at $23{ }^{\circ} \mathrm{C}$ for $5 \mathrm{~min}$ with gentle agitation. After incubation, the tubes were centrifuged for $20 \mathrm{~s}$ at $5000 \mathrm{~g}$, and the RNA supernatant was transferred to a separate tube. The RNA solution was subjected again to heating $\left(65^{\circ} \mathrm{C}\right)$, cooled on ice, and re-incubated with the Oligo $(\mathrm{dT})_{25}$ cellulose beads as above; this procedure was repeated 3 times. The Oligo $(\mathrm{dT})_{25}$ cellulose beads were then suspended in $0.5 \mathrm{~mL}$ loading buffer, transferred to a Centrifugal Filter Unit (Millipore) and centrifuged for $20 \mathrm{~s}$. The beads in the filter unit were washed 4 more times with loading buffer, and 1 time in low salt buffer $(0.1 \mathrm{M} \mathrm{NaCl}, 20 \mathrm{mM}$ Tris-HCl, $\mathrm{pH} 7.5,1 \mathrm{mM}$ EDTA). Poly-A mRNA was eluted with $2 \times 250 \mu \mathrm{L}$ elution buffer $(20 \mathrm{mM}$ Tris-HCl, $\mathrm{pH} 7.5)$, followed by RNA precipitation as in the manufacturer's protocol.

Only cases with relatively well-preserved RNA integrity (as defined by RNA Integrity Number [RIN] from an Agilent Bioanalyzer $2100>$ 4.0, Agilent hails from Santa Clara, CA, USA) were included. Based on this criterion, three cases for which RNA was isolated were not included in this study because of degraded RNA. Final number of samples used was 20 (two brain areas each from 10 different research subjects). The average RIN value was $>8.0$ for included cases (Table 2) and there was no difference detected in RIN values between the various groups.

\section{3'RACE: PCR and cloning}

To characterize various transcript variants of $3^{\prime} \mathrm{UTR}$, Marathon cDNA amplification kit (Clontech, Clontech-Mountain View, CA, USA) was used for 3'RACE. First-strand cDNA was synthesized using poly-A RNA isolated from human hippocampal and skeletal muscle tissues. The synthesis of second-strand cDNA and adapter ligation was performed according to manufacturer's instructions. ABCC9 gene-specific primers (Table S1) located in Exon38 and Exon39 were designed as forward primers in combination with reverse adopter primer 1 or adaptor primer 2 (supplied with the kit) to amplify $3^{\prime}$ ends of the cDNA. Amplified products were then cloned into PCR cloning vectors Zero-blunt or pCR-XL Topo (Life Technologies, Grand Island, NY, USA). Positive clones were examined by restriction enzyme digestion, and confirmed by sequencing (AGTC, University of Kentucky). Sequencing data were analyzed using NCBI/blastn suite (http://blast.ncbi.nlm.nih.-gov), and UCSC Genome Brower (http://genome.ucsc.edu/). Multiple sequence alignment was carried out by using EMBL-EBI's Clustal Omega (https://www.ebi.ac.uk/Tools/msa/clustalo/). 


\section{Reverse transcription and PCR (RT-PCR and RT-qPCR)}

Total RNA (500 ng) isolated from human tissues was converted into cDNA using Superscript III reverse transcription (RT) kit (Life Technologies) following manufacturer's protocol. The cDNA served as templates for PCR including quantitative real-time PCR (qPCR). Platinum Taq DNA polymerase (Life Technologies) was used in both regular and real-time qPCR. Real-time PCR was carried out in ABI 7000 with SYBR Green as detecting dye. An equivalent quantity of cDNA (10 or $20 \mathrm{ng}$ ) was used in the PCR or qPCR. Actin primers were reported previously (Wang et al. 2010a) and here were used as reference in normalizing expression levels. Gene-specific primers used in these experiments are listed in Table S1.

\section{Statistical methods}

For studies of public access web servers, we relied on the web servers themselves to provide data and statistical tests, and neither further tests nor any other additional analyses were performed on these data (see additional text in Supporting Information). For analyzing qPCR results, the data from three separate qPCR runs (median value) were normalized to three separate qPCR runs (also the median values) for ( $\beta$-Actin from the same RT reaction. Descriptive statistics were performed using Microsoft Excel (Microsoft-Seattle, WA, USA). Student's $t$-tests were used to compare groups (mean values) and Pearson's correlation was used to test for linear relationships between qPCR amplicons. For the miRNA transfection experiments, simple linear regression was used to test for the replicate averaged $\mathrm{Ct}$ (qPCR) values compared between miRNA assays and control. Batch effects were adjusted for via inclusion in the regression model.

\section{MicroRNA (miRNA) transfection in $\mathrm{H} 4$ cells to test differential effect on long versus short SUR2 3'UTR}

MicroRNA mimics (from Ambion-Life Technologies, Ambion-Grand Island, NY, USA) were used referent to hsa-miR-30c-5p (MIMAT0000244), hsa-miR-200c-3p (MEVIAT0000617), and 'Negative Control \#1'. For each, $100 \mathrm{nM}$ was used to transfect H4 cells (Arnstein et al. 1974) using RNAiMAX (Life Technologies) according to the manufacturer's instructions. Cells were harvested $48 \mathrm{~h}$ post transfection, and RNA was isolated and RT-qPCR performed as described above. Three independent experiments were performed with five replicates in each experiment, for a total of 15 biologic replicates per miRNA transfected.

\section{Results}

\section{In silico studies to address whether rs704180 is a local eQTL}

For a schematic overview of $A B C C 9$ genomic arrangement, including $3^{\prime}$ exons and previously identified risk alleles, see Fig. 1; note that the risk alleles cluster in the $3^{\prime}$ portion of the gene. Web servers and datasets used in this study are described in Table 1. Primary data from those web servers are presented in Fig. 2-5; each was queried specifically about whether rs704180 is a cis/local eQTL for SUR2 transcript levels. Data analyses using the 'SNPExp' website enabled study of correlation between SNP status and transcript levels in 
lymphoblastoid cells transformed with human DNA from multiple research volunteers $(n=$ 269). Specifically, the presence of the rs704180 risk allele (A_A) was associated with increased expression of the $A B C C 9$ gene product, SUR $2 \mathrm{mRNA}$ (for this web server the queried transcript was GI_10947123-A). This is compatible with the hypothesis that rs704180 is a cis (local) eQTL, and the risk genotype is correlated with increased transcript levels.

A second database that was queried was the 'GTEx' web server evaluating the human neuroanatomical area ('caudate and basal ganglia') that included the highest number of samples ( $n=34$ total) among the different brain areas assessed. These analyses indicate that rs704180 is an eQTL in human brain ( $p=0.01$; Fig. 3 ). The other brain tissues available for eQTL analyses through the GTEx web server all had $n<30$ and higher $p$ values with the exception of 'nucleus accumbens' $(n=30)$ which returned $p=0.08$ for rs704180 and $p=$ 0.04 for nearby rs704192 (data not shown). We note that the population frequency of rs704180 varies, depending on study cohort, such that the minor allele may be either A or G, depending on the cohort demographics (Nelson et al. 2014). In the GTEx data the identification of the allele (A versus $\mathrm{G}$ ) is not specified.

The third and final public access database analyzed was the 'BRAINEAC web server that included analyses from multiple human brain areas from 133 research volunteers, focusing on the expression of the $A B C C 9$ gene product, SUR2 (Affymetrix transcript ID t3446919, Affymetrix-Santa Clara, CA, USA). These data again supported the hypothesis that the rs704180 risk allele (A_A) is associated with increased expression of SUR2B mRNA ( $p=$ 0.01; Fig. 4). Additional data analyses were performed using the 'BRAINEAC website because this web tool enabled evaluation of the association between SNP status and individual exon levels (within a transcript) in brain tissue. We queried the association between rs704180 allele status and expression of individual exons from the $3^{\prime}$ portion of SUR2 mRNA: Affymetrix transcript IDs 3446921 and 3446922/3'UTR, 3446923/Exon 38, 3446925/Exon 37, 3446926/Exon 36, and 3446927/Exon 35. Shown are data expressing $p$ values for each particular exon/SNP association, for all the brain areas combined (Fig. 5). These data provide additional support for the hypothesis that rs704180 status is associated with different expression of Exons 36, 37, and Exon 39 (SUR2B), and the distal 3'UTR, but not Exon 38 (SUR2A) nor the proximal 3'UTR.

\section{Characterizing SUR2 variants expressed in human brain and directly testing whether rs704180 is an eQTL in brain tissue}

Cases were selected from the University of Kentucky Alzheimer's Disease Center (UK-

ADC) biobank (Table 2). Information about this research cohort, biobank, neuropathological practices, and SNP genotyping are provided in detail elsewhere (Nelson et al. 2009, 2014;

Schmitt et al. 2012). Cases were selected to represent two groups, those with both HS-Aging pathology and the AA genotype of rs704180, and patients lacking HS-Aging pathology and with the GG genotype of rs704180.

Following RNA isolation and reverse transcription, $3^{\prime}$ RACE revealed novel SUR2 transcript variants and 3'UTR ends (Fig. 6). Notably, a transcript containing Exon38 with a previously unknown 3'UTR was identified in human brain tissue (Fig. 6). We designated this transcript 
as SUR2A. We also identified a second Exon38-containing transcript that also included the entire length of Exon39; this transcript was evident in human skeletal muscle and other tissues including brain (Figs. 6-8). This is probably the SUR2 transcript variant reported as $S U R 2 A$ in prior studies (see below). We now designated this transcript as $S U R 2 A b$. For $S U R 2 A b$, Exon39 may not be translated into a polypeptide since a stop codon is present at the end of Exon38 (Fig. 7). However, the $S U R 2 A b$ has a completely different $3^{\prime}$ UTR in comparison to $S U R 2 A$. The $S U R 2 A b$ transcript identified by RACE/sequencing bears a 3'UTR that is identical to 445 bp of the annotated SUR2B 3'UTR (NM_020297.3). In addition to that variant, 3'RACE identified several 3'UTR variants that contain Exon39 (Fig. 6, UTR-1.3 kb, UTR-445 bp, UTR-204 bp). These variant 3'UTR s share identical proximal sequence with the previously deposit SUR2B transcript (NM_020297.3).

Expression of $S U R 2$ transcript variants $S U R 2 A, S U R 2 B$, and $S U R 2 A b$ was examined in human tissues using RT-PCR. Tailored primers (Fig. 8, Table S1) were applied that could detect specifically each of the $S U R 2$ transcript variants. These studies validated the previously described widespread expression of $S U R 2 B$, and the novel SUR2A 3'UTR portion, while also enabling a comparison of $S U R 2$ transcripts in human brain cases stratifying by rs 704180 genotype. SUR $2 B$ was readily detected in all tissues tested. SUR $2 A$ and $S U R 2 A b$ were also detected in many tissues (Fig. 8, Figure S1 and 2); however, these transcripts were detected at higher levels in skeletal muscle and heart (Fig. 8). Expression levels of $A B C C 9$ Exon38 and Exon39 in SUR transcripts, as well as proximal and distal portion of the $S U R 2 B 3^{\prime} \mathrm{UTR}$, were evaluated in human brain tissues with or without the rs704180 risk genotype (Fig. 9). RT-qPCR demonstrated that Exon39 (SUR2B and SUR2Ab) levels were detected at higher levels in brain tissues from patients with the rs704180 risk genotype. Interestingly, detection of the distal portion of the SUR $2 B 3^{\prime}$ UTR was negatively correlated with SUR2B (Figure S3). We interpret these data, alongside the in silico analyses of public domain data (above), to be compatible with the hypothesis that the rs704180 genotype leads to enrichment of a shorter $S U R 2 B 3^{\prime}$ UTR and a possibly more stable $S U R 2 B$ transcript, in human brain tissue.

\section{MiRNA transfection in $\mathrm{H} 4$ cells to test differential effect on long versus short SUR2 $3^{\prime}$ UTR}

Since discovering that the length of the $3^{\prime}$ UTR was associated with a change in transcript levels, we wanted to test for a possible mechanism. One mechanism by which $3^{\prime} \mathrm{UTR}$ sequence confers altered mRNA stability is through providing a target for miRNA binding (Guo et al. 2010). We found that there were predicted miRNA targets in the $3^{\prime} \mathrm{UTR}$ of SUR2. Specifically, TargetScan6.2 (http://www.targetscan.org/) predicted that there are evolutionarily conserved miRNA recognition elements for miR-30 and miR-200 paralogs (Fig. 10). We tested the specific hypothesis that miR-30c, which has putative recognition elements near the $3^{\prime}$ end of the long version of the SUR2 $3^{\prime}$ UTR, would alter the proportion of SUR 2 transcripts harboring a sequence near the $5^{\prime}$ end of the $3^{\prime} \mathrm{UTR}$, versus a sequence near the $3^{\prime}$ end of the $3^{\prime}$ UTR (Fig. 11). For these experiments we used H4 cells which have a 'glioneuronal' phenotype (Arnstein et al. 1974), and which we have used in prior miRNA transfections (Wang et al. 2010a,b). Employing a directional (i.e., 1-sided) hypothesis test, for average miR-30c differences being less than those for the negative control, resulted in a $p$-value of 0.026 . When testing for miR-200c differences being greater than control, the 
resulting $p$-value is 0.091 . If these tests were two-sided, neither would be significant at the $5 \%$ nominal alpha level (for the two-sided test, $p=0.052$ and 0.183 , respectively). The data indicate that miR-30c leads to a relative increase in the proportion of $3^{\prime} \mathrm{UTR}$ amplicons from the $5^{\prime}$ end, in comparison to amplicons from the $3^{\prime}$ end, as predicted. This is compatible with the hypothesis that miR-30c binding is one mechanism underlying the relative instability of SUR2 transcripts that harbor the longer $3^{\prime} \mathrm{UTR}$.

\section{Discussion}

We report evidence of complex genetic regulation of the $A B C C 9$ gene in the human brain. Our study employed experimental and in silico analyses, focusing on the $3^{\prime}$ portion of gene. Prior annotation of the $A B C C 9$ was incomplete. We describe novel human $S U R 2$ transcripts, including 3'UTR variants. Furthermore, we find evidence that a SNP (rs704180) associated with risk for HS-Aging pathology is a 'cis' (local) eQTL for ABCC9. The data indicate that rs704180 is associated with a shorter $3^{\prime} \mathrm{UTR}$ that is also correlated with increased SUR2B transcript level in those samples. One mechanism that may underlie the relative instability of the SUR2 transcript with the longer 3'UTR is down-regulation by miR-30 paralogs such as miR-30c. As far we know this is the first detailed analysis of transcripts and expression patterns of SUR2 in post-mortem human brain.

Although we report here some SUR2 splice variants that were not yet annotated, there previously were indications for the existence of some of those transcripts. Prior studies showed that a splice variant exists with both Exon38 and Exon39 included (Isomoto et al. 1996; Davis-Taber et al. 2000; Ye et al. 2009). Importantly, mice have been shown to express full-length transcripts harboring both exons (Isomoto et al. 1996). It is theoretically possible that a read-through of that stop codon could occur during some conditions, leading to a true Exon 37-38-39 containing SUR2AB polypeptide, but testing that hypothesis would require substantial additional experiments. We know of no previous description of a SUR2A-specific 3'UTR, which is a potentially important novel observation, although it was detected with $3^{\prime}$ RACE only. Considering the prior literature and our data together, it is probable that full-length versions of the splice variants described in this study are expressed in brain, in other human tissues, and in many other organisms. We also note that prior studies have reported clones and expressed sequence tags that indicate the presence of differently sized SUR2B 3'UTRs (e.g., see expressed sequence tag clones AK_094171 and AK_092535 from Ref, Ota et al. 2004), but these also were not full-length clones. There also are shorter, $5^{\prime}$ end annotated SUR2 transcripts with completely different $3^{\prime}$ UTRs (ENST00000538350 and ENST00000326684), which is an additional level of complexity. Future work is required to better understand the RNA processing factors responsible for the many splicing events linked to $A B C C 9 /$ SUR 2 function.

Our interest in $A B C C 9$ stems from discovery of an intronic risk allele (rs704180) for HSAging (Nelson et al. 2014, 2015). HS-Aging is a neurodegenerative disease that mimics Alzheimer's disease (AD) clinically, and is common in the aged population - the prevalence of HS-Aging in autopsy series is up to 25\% among the 'oldest-old' (Nelson et al. 2013; Brenowitz et al. 2014). The neuropathology of HS-Aging is characterized by cell loss and astrocytosis in the hippocampal formation that is out of proportion to the AD-type plaques 
and tangles (Montine et al. 2012). Pathogenetic mechanism(s) of HS-Aging are incompletely understood, but may relate to arteriolar vascular disease, and/or a neurodegenerative disease class referred to as frontotemporal lobar degeneration (Nelson et al. 2013; Brenowitz et al. 2014; Neltner et al. 2014). There have not been many prior studies of $A B C C 9$ in neurodegenerative disease research, but a systematic study of molecular pathways disrupted in $A B C C 9$ knockout mice identified AD-related molecular variation as the single most impacted pathway associated with that molecular lesion (Gao et al. 2014). As SUR2 function has been linked to cellular response to injury in many contexts (Olson and Terzic 2010; Nichols et al. 2013), and is targetable by various drugs, the protein represents a credible molecular target for potential disease modification as was recently pointed out (Nelson et al. 2014; Macauley et al. 2015).

One unexpected outcome from these analyses is that the risk genotype for HS-Aging, rs704180 A_A, is associated with relatively high levels of SUR2B transcripts in the postmortem aged human brain, and also in transformed human-derived lymphoblastoid cells. The reason we did not expect this result is that we found previously that exposure to a drug class (sulfonylureas) that antagonizes SUR2 activity is associated with increased HS-Aging pathology among individuals over 85 years of age at death in the National Alzheimer's Coordinating Center cohort (Nelson et al. 2014). Therefore, we had hypothesized that the $A B C C 9$ risk genotypes would be associated with decreased SUR2 expression - the opposite of what was observed. There are at least three possible explanations for this apparent discrepancy. First, the prior published analyses (Nelson et al. 2014) may have yielded 'falsepositive' results; the association between sulfonylurea drug exposure and HS-Aging pathology was not particularly strong $(p<0.03$ ), so may have been the result of random variation. Second, the individuals with greatest risk for HS-Aging pathology may indeed be those with higher, not lower, SUR2 levels in brain, since those persons may be relatively dependent on this molecular pathway and thus more vulnerable to a drug that antagonizes SUR2 function. A third possibility is that the direct impact of sulfonylureas may be exerted on the brain through $A B C C 8 / S U R I$ rather than $A B C C 9 /$ SUR2. Indeed the therapeutic effect of sulfonylureas is exerted through antagonizing pancreatic SUR1 for diabetes control (Proks et al. 2002; Nagashima et al. 2004). To date, there has been more scholarship published on potential associations between $A B C C 8 /$ SURI and brain pathologies (Jiang et al. 2007; Mehta et al. 2013; Jayakumar et al. 2014) than ABCC9/SUR2. However, we could find no signal in terms of gene polymorphisms in $A B C C 8$ being associated with HS-Aging risk (data not shown).

Some factors and potential limitations should be taken into account when interpreting these experiments. The number of samples used in our human brain tissue analyses was low in terms of statistical power, so our results require further replication. Although we use levels of cDNA from processed human brain samples as a signifier of 'gene expression', the relevance to protein 'expression' is not assured, because many factors affect polypeptide levels after mRNA transcription; mRNA translation is another key node of gene expression regulation so mRNA and protein levels are often poorly correlated (Nelson and Keller 2007). The 3'UTR of SUR2 mRNA, which we here describe to have alternative start-and end-sites in human brain, may regulate translational efficiency, transcript stability, cellular 
domain localization, and other factors. It was previously reported that the $3^{\prime}$ UTR of SUR2 may affect mRNA stability (Yang et al. 2012) and artifactual variation including postmortem changes cannot be completely ruled out. Furthermore, although we found evidence that rs704180 is an eQTL for ABCC9, that particular SNP could well be a proxy for more complex genomic features including the many SNPs that are in linkage disequilibrium with rs704180. We previously reported that SNPs associated with risk for HS-Aging span at least ten different introns of the ABCC9 gene (Nelson et al. 2014). The study of eQTLs is made challenging because the genotype/transcript change may be labile to anatomical region, cell type(s), agonal state of the patient, and other factors. Our study of eQTL was focused on the single SNP, and therefore both unconventional and also blind to other polymorphisms that may be associated with altered expression of the $A B C C 9$ gene.

A basic unanswered question is: which cell or tissue compartment(s) is/are important in a clinical-pathological sense? For example, SUR2A and SUR2B proteins are expressed in arteriolar smooth muscle cells, endothelial cells, pericytes, neurons, astrocytes, microglia, oligodendrocytes, and many other CNS cells (see, Lee et al. 1998; Zawar et al. 1999;

Pelletier et al. 2000; Bondjers et al. 2006; Lacza et al. 2003; Zhou et al. 2012), and thus the overall impact on human diseases such as HS-Aging may reflect a complicated synergy. Unfortunately, there is no animal (much less cellular) model of HS-Aging, and thus no other known context that could serve as an accurate experimental system to study pathogenetic changes related directly to HS-Aging, other than the aged human brain itself.

The profound complexity and uniqueness of human brain pathologies therefore indicates the appropriateness of caution in interpreting our results, while at the same time confirming the need for more human brain analyses. We were gratified to be able to utilize some of the expanding repertoire of research tools - including human biobanks, improved genomic annotation, and publicly accessible genome databases and web servers - to study human brain biology. Using these resources enabled discovery of evidence for novel gene expression phenomena in the $A B C C 9$ gene that are perhaps relevant to human diseases.

\section{Supplementary Material}

Refer to Web version on PubMed Central for supplementary material.

\section{Acknowledgments}

We are extremely grateful to all the research volunteers, clinicians, staff members and others that contributed to the clinical research, including participants at the UK-ADC and also the sites worldwide. See Supporting Information for more acknowledgments. This work was supported by the National Institutes of Health grants [K25 AG043546 to DF, P30 AG028383 to PTN].

All experiments were conducted in compliance with the ARRIVE guidelines.

\section{Abbreviations used}
AD
Alzheimer's disease
HS-Aging
hippocampal sclerosis of aging 


$\begin{array}{ll}\text { RIN } & \text { RNA integrity number } \\ \text { SNPs } & \text { single nucleotide polymorphisms } \\ \text { SUR2 } & \text { sulfonylurea receptor } 2\end{array}$

\section{References}

Allebrandt KV, Amin N, Muller-Myhsok B, et al. A K(ATP) channel gene effect on sleep duration: from Genome-Wide Association Studies to function in Drosophila. Mol Psychiatry. 2013; 18:122132. [PubMed: 22105623]

Arnstein P, Taylor DO, Nelson-Rees WA, Huebner RJ, Lennette EH. Propagation of human tumors in antithymocyte serum-treated mice. J. Natl Cancer Inst. 1974; 52:71-84. [PubMed: 4544026]

Bienengraeber M, Olson TM, Selivanov VA, et al. ABCC9 mutations identified in human dilated cardiomyopathy disrupt catalytic KATP channel gating. Nat. Genet. 2004; 36:382-387. [PubMed: 15034580]

van Bon BW, Gilissen C, Grange DK, et al. Cantu syndrome is caused by mutations in ABCC9. Am. J. Hum. Genet. 2012; 90:1094-1101. [PubMed: 22608503]

Bondjers C, He L, Takemoto M, Norlin J, Asker N, Hellstrom M, Lindahl P, Betsholtz C. Microarray analysis of blood microvessels from PDGF-B and PDGF-Rbeta mutant mice identifies novel markers for brain pericytes. FASEB J. 2006; 20:1703-1705. [PubMed: 16807374]

Brenowitz WD, Monsell SE, Schmitt FA, Kukull WA, Nelson PT. Hippocampal sclerosis of aging is a key Alzheimer's disease mimic: clinical-pathologic correlations and comparisons with both Alzheimer's disease and non-tauopathic frontotemporal lobar degeneration. J. Alzheimers Dis. 2014; 39:691-702. [PubMed: 24270205]

Chutkow WA, Simon MC, Le Beau MM, Burant CF. Cloning, tissue expression, and chromosomal localization of SUR2, the putative drug-binding subunit of cardiac, skeletal muscle, and vascular KATP channels. Diabetes. 1996; 45:1439-1445. [PubMed: 8826984]

Chutkow WA, Makielski JC, Nelson DJ, Burant CF, Fan Z. Alternative splicing of sur2 Exon 17 regulates nucleotide sensitivity of the ATP-sensitive potassium channel. J. Biol. Chem. 1999; 274:13656-13665. [PubMed: 10224138]

Chutkow WA, Pu J, Wheeler MT, Wada T, Makielski JC, Burant CF, McNally EM. Episodic coronary artery vasospasm and hypertension develop in the absence of Sur2 K (ATP) channels. J. Clin. Investig. 2002; 110:203-208. [PubMed: 12122112]

The GTEx Consortium. The genotype-tissue expression (GTEx) project. Nat. Genet. 2013; 45:580585. [PubMed: 23715323]

Czeschik JC, Voigt C, Goecke TO, Ludecke HJ, Wagner N, Kuechler A, Wieczorek D. Wide clinical variability in conditions with coarse facial features and hypertrichosis caused by mutations in ABCC9. Am. J. Med. Genet. A. 2013; 161A:295-300. [PubMed: 23307537]

Davis-Taber R, Choi W, Feng J, et al. Molecular characterization of human SUR2-containing K(ATP) channels. Gene. 2000; 256:261-270. [PubMed: 11054556]

Elrod JW, Harrell M, Flagg TP, Gundewar S, Magnuson MA, Nichols CG, Coetzee WA, Lefer DJ. Role of sulfonylurea receptor type 1 subunits of ATP-sensitive potassium channels in myocardial ischemia/reperfusion injury. Circulation. 2008; 117:1405-1413. [PubMed: 18316485]

Flagg TP, Enkvetchakul D, Koster JC, Nichols CG. Muscle KATP channels: recent insights to energy sensing and myoprotection. Physiol. Rev. 2010; 90:799-829. [PubMed: 20664073]

Gao J, Xu D, Sabat G, Valdivia H, Xu W, Shi NQ. Disrupting KATP channels diminishes the estrogen-mediated protection in female mutant mice during ischemia-reperfusion. Clin. Proteomics. 2014; 11:19. [PubMed: 24704857]

Guo H, Ingolia NT, Weissman JS, Bartel DP. Mammalian microRNAs predominantly act to decrease target mRNA levels. Nature. 2010; 466:835-840. [PubMed: 20703300]

Harakalova M, van Harssel JJ, Terhal PA, et al. Dominant missense mutations in ABCC9 cause Cantu syndrome. Nat. Genet. 2012; 44:793-796. [PubMed: 22610116] 
Holm K, Melum E, Franke A, Karlsen TH. SNPexp - A web tool for calculating and visualizing correlation between HapMap genotypes and gene expression levels. BMC Bioinformatics. 2010; 11:600. [PubMed: 21167019]

Inagaki N, Gonoi T, Clement JP, Wang CZ, Aguilar-Bryan L, Bryan J, Seino S. A family of sulfonylurea receptors determines the pharmacological properties of ATP-sensitive $\mathrm{K}+$ channels. Neuron. 1996; 16:1011-1017. [PubMed: 8630239]

Isomoto S, Kondo C, Yamada M, Matsumoto S, Higashiguchi O, Horio Y, Matsuzawa Y, Kurachi Y. A novel sulfonylurea receptor forms with BIR (Kir6.2) a smooth muscle type ATP-sensitive K+ channel. J. Biol. Chem. 1996; 271:24321-24324. [PubMed: 8798681]

Jayakumar AR, Valdes V, Tong XY, Shamaladevi N, Gonzalez W, Norenberg MD. Sulfonylurea receptor 1 contributes to the astrocyte swelling and brain edema in acute liver failure. Transl. Stroke Res. 2014; 5:28-37. [PubMed: 24443056]

Jiang K, Yu Z, Shui Q. The pattern of ATP-sensitive K+ channel subunits, Kir6.2 and SUR1 mRNA expressions in DG region is different from those in CA1-3 regions of chronic epilepsy induced by picrotoxin in rats. Neuropathology. 2007; 27:531-538. [PubMed: 18021373]

Lacza Z, Snipes JA, Kis B, Szabo C, Grover G, Busija DW. Investigation of the subunit composition and the pharmacology of the mitochondrial ATP-dependent $\mathrm{K}+$ channel in the brain. Brain Res. 2003; 994:27-36. [PubMed: 14642445]

Lee K, Dixon AK, Freeman TC, Richardson PJ. Identification of an ATP-sensitive potassium channel current in rat striatal cholinergic interneurones. J. Physiol. 1998; 510(Pt 2):441-453. [PubMed: 9705995]

Macauley SL, Stanley M, Caesar EE, Yamada SA, Raichle ME, Perez R, Mahan TE, Sutphen CL, Holtzman DM. Hyperglycemia modulates extracellular amyloid-beta concentrations and neuronal activity in vivo. J Clin Invest. 2015; 125:2463-2467. [PubMed: 25938784]

Mehta RI, Ivanova S, Tosun C, Castellani RJ, Gerzanich V, Simard JM. Sulfonylurea receptor 1 expression in human cerebral infarcts. J. Neuropathol. Exp. Neurol. 2013; 72:871-883. [PubMed: 23965746]

Minoretti P, Falcone C, Aldeghi A, Olivieri V, Mori F, Emanuele E, Calcagnino M, Geroldi D. A novel Val734Ile variant in the ABCC9 gene associated with myocardial infarction. Clin. Chim. Acta. 2006; 370:124-128. [PubMed: 16563363]

Montine TJ, Phelps CH, Beach TG, et al. National Institute on Aging-Alzheimer's Association guidelines for the neuropathologic assessment of Alzheimer's disease: a practical approach. Acta Neuropathol. 2012; 123:1-11. [PubMed: 22101365]

Moore HM. Acquisition of normal tissues for the GTEx program. Biopreserv. Biobank. 2013; 11:7576. [PubMed: 24845427]

Nagashima K, Takahashi A, Ikeda H, Hamasaki A, Kuwamura N, Yamada Y, Seino Y. Sulfonylurea and non-sulfonylurea hypoglycemic agents: pharmachological properties and tissue selectivity. Diabetes Res. Clin. Pract. 2004; 66(Suppl 1):S75-S78. [PubMed: 15563985]

Nelson PT, Keller JN. RNA in brain disease: no longer just "the messenger in the middle". J. Neuropathol. Exp. Neurol. 2007; 66:461-468. [PubMed: 17549006]

Nelson PT, Abner EL, Schmitt FA, Kryscio RJ, Jicha GA, Santacraz K, Smith CD, Patel E, Markesbery WR. Brains with medial temporal lobe neurofibrillary tangles but no neuritic amyloid plaques are a diagnostic dilemma but may have pathogenetic aspects distinct from Alzheimer disease. J. Neuropathol. Exp. Neurol. 2009; 68:774-784. [PubMed: 19535994]

Nelson PT, Smith CD, Abner EL, et al. Hippocampal sclerosis of aging, a prevalent and highmorbidity brain disease. Acta Neuropathol. 2013; 126:161-177. [PubMed: 23864344]

Nelson PT, Estus S, Abner EL, et al. ABCC9 gene polymorphism is associated with hippocampal sclerosis of aging pathology. Acta Neuropathol. 2014; 127:825-843. [PubMed: 24770881]

Nelson PT, Wang WX, Partch AB, et al. Reassessment of risk genotypes (GRN, TMEM106B, and ABCC9 variants) associated with hippocampal sclerosis of aging pathology. J. Neuropathol. Exp. Neurol. 2015; 74:75-84. [PubMed: 25470345]

Neltner JH, Abner EL, Baker S, et al. Arteriolosclerosis that affects multiple brain regions is linked to hippocampal sclerosis of ageing. Brain. 2014; 137:255-267. [PubMed: 24271328] 
Nichols CG, Singh GK, Grange DK. KATP channels and cardiovascular disease: suddenly a syndrome. Circ. Res. 2013; 112:1059-1072. [PubMed: 23538276]

Olson TM, Terzic A. Human K(ATP) channelopathies: diseases of metabolic homeostasis. Pflugers Arch. 2010; 460:295-306. [PubMed: 20033705]

Olson TM, Alekseev AE, Moreau C, et al. KATP channel mutation confers risk for vein of Marshall adrenergic atrial fibrillation. Nat. Clin. Pract. Cardiovasc. Med. 2007; 4:110-116. [PubMed: 17245405]

Ota T, Suzuki Y, Nishikawa T, et al. Complete sequencing and characterization of 21,243 full-length human cDNAs. Nat. Genet. 2004; 36:40-45. [PubMed: 14702039]

Parsons MJ, Lester KJ, Barclay NL, Nolan PM, Eley TC, Gregory AM. Replication of Genome-Wide Association Studies (GWAS) loci for sleep in the British G1219 cohort. Am. J. Med. Genet. B Neuropsychiatr. Genet. 2013; 162B:431-438. [PubMed: 23780892]

Pelletier MR, Pahapill PA, Pennefather PS, Carlen PL. Analysis of single K(ATP) channels in mammalian dentate gyrus granule cells. J. Neurophysiol. 2000; 84:2291-2301. [PubMed: 11067973]

Ploug KB, Baun M, Hay-Schmidt A, Olesen J, Jansen-Olesen I. Presence and vascular pharmacology of KATP channel subtypes in rat central and peripheral tissues. Eur. J. Pharmacol. 2010; 637:109117. [PubMed: 20361954]

Proks P, Reimann F, Green N, Gribble F, Ashcroft F. Sulfonylurea stimulation of insulin secretion. Diabetes. 2002; 51(Suppl 3):S368-S376. [PubMed: 12475777]

Ramasamy A, Trabzuni D, Guelfi S, et al. Genetic variability in the regulation of gene expression in ten regions of the human brain. Nat. Neurosci. 2014; 17:1418-1428. [PubMed: 25174004]

Schmitt FA, Nelson PT, Abner E, et al. University of Kentucky Sanders-Brown healthy brain aging volunteers: donor characteristics, procedures and neuropathology. Curr. Alzheimer Res. 2012; 9:724-733. [PubMed: 22471862]

Seino S, Miki T. Physiological and pathophysiological roles of ATP-sensitive K+ channels. Prog. Biophys. Mol. Biol. 2003; 81:133-176. [PubMed: 12565699]

Shi NQ, Ye B, Makielski JC. Function and distribution of the SUR isoforms and splice variants. J. Mol. Cell. Cardiol. 2005; 39:51-60. [PubMed: 15978902]

Shi WW, Yang Y, Shi Y, Jiang C. K(ATP) channel action in vascular tone regulation: from genetics to diseases. Sheng Li Xue Boo. 2012; 64:1-13.

Smith KJ, Chadburn AJ, Adomaviciene A, Minoretti P, Vignali L, Emanuele E, Tammaro P. Coronary spasm and acute myocardial infarction due to a mutation (V734I) in the nucleotide binding domain 1 of ABCC9. Int. J. Cardiol. 2013; 168:3506-3513. [PubMed: 23739550]

Wang WX, Wilfred BR, Hu Y, Sternberg AJ, Nelson PT. Anti-Argonaute RIP-Chip shows that miRNA transfections alter global patterns of mRNA recruitment to microribonucleoprotein complexes. RNA. 2010a; 16:394-404. [PubMed: 20042474]

Wang WX, Wilfred BR, Xie K, Jennings MH, Hu YH, Stromberg AJ, Nelson PT. Individual microRNAs (miRNAs) display distinct mRNA targeting "rules". RNA Biol. 2010b; 7:373-380. [PubMed: 20421741]

Wang WX, Danaher RJ, Miller CS, Berger JR, Nubia VG, Wilfred BS, Neltner JH, Norris CM, Nelson PT. Expression of miR-15/107 family microRNAs in human tissues and cultured rat brain cells. Genomics Proteomics Bioinformatics. 2014; 12:19-30. [PubMed: 24480177]

Wang WX, Visavadiya NP, Pandya JD, Nelson PT, Sullivan PG, Springer JE. Mitochondria-associated microRNAs in rat hippocampus following traumatic brain injury. Exp. Neurol. 2015; 265:84-93. [PubMed: 25562527]

Yang Y, Li S, Konduru AS, et al. Prolonged exposure to methylglyoxal causes disruption of vascular KATP channel by mRNA instability. Am. J. Physiol. Cell Physiol. 2012; 303:C1045-C1054. [PubMed: 22972803]

Ye B, Kroboth SL, Pu JL, Sims JJ, Aggarwal NT, McNally EM, Makielski JC, Shi NQ. Molecular identification and functional characterization of a mitochondrial sulfonylurea receptor 2 splice variant generated by intraexonic splicing. Circ. Res. 2009; 105:1083-1093. [PubMed: 19797704] 
Zawar C, Plant TD, Schirra C, Konnerth A, Neumcke B. Cell-type specific expression of ATPsensitive potassium channels in the rat hippocampus. J. Physiol. 1999; 514(Pt 2):327-341. [PubMed: 9852317]

Zhang H, Flagg TP, Nichols CG. Cardiac sarcolemmal K (ATP) channels: latest twists in a questing tale! J. Mol. Cell. Cardiol. 2010; 48:71-75. [PubMed: 19607836]

Zhou M, He HJ, Tanaka O, Sekiguchi M, Kawahara K, Abe H. Localization of the ATP-sensitive K(+) channel regulatory subunits SUR2A and SUR2B in the rat brain. Neurosci. Res. 2012; 74:91-105. [PubMed: 22960600] 

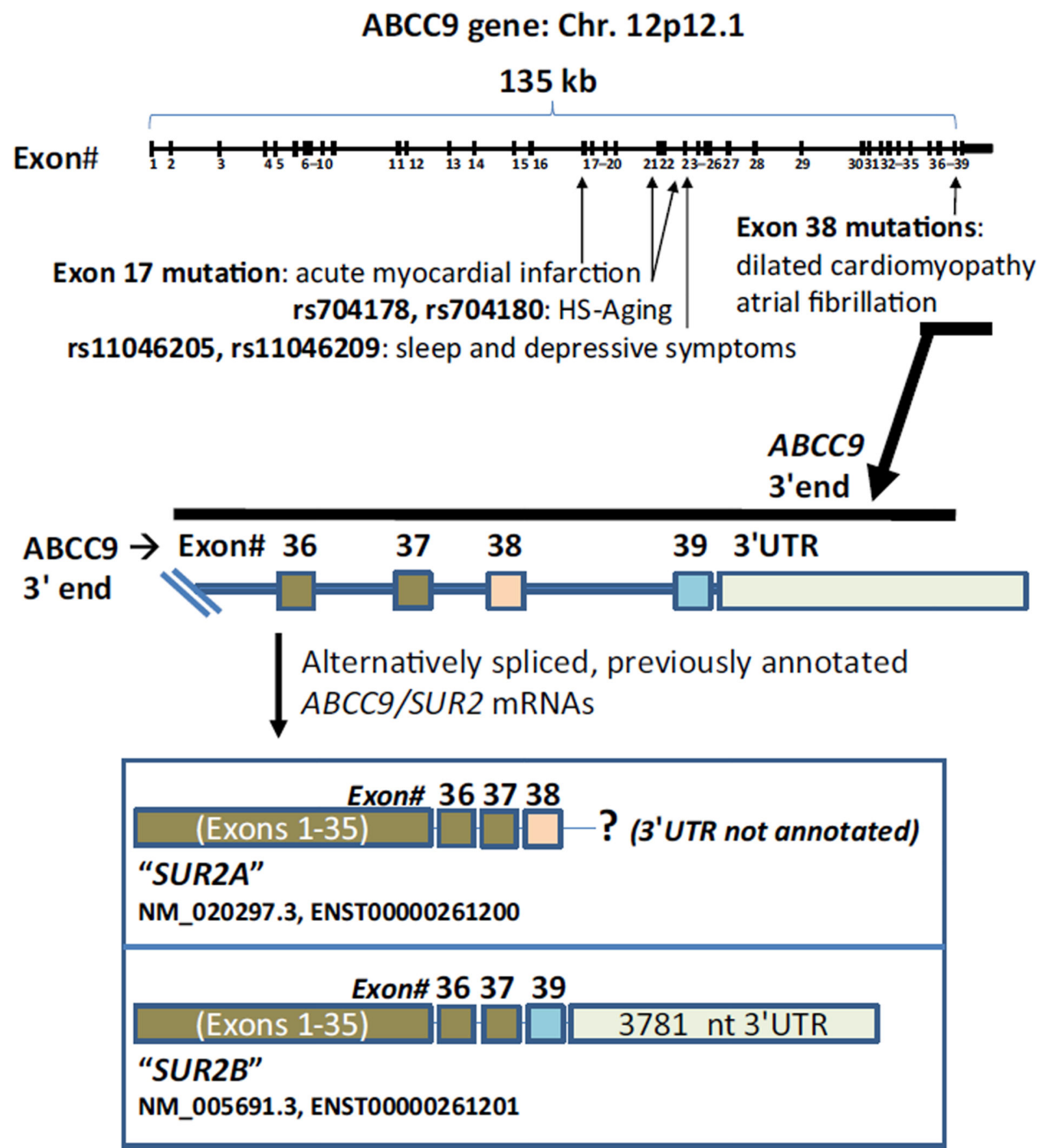

Fig. 1.

Schematic depiction of the $A B C C 9$ gene including known polymorphisms that are associated with differential risk for human diseases. Citations for these risk alleles are Refs (Bienengraeber et al. 2004; Minoretti et al. 2006; Olson et al. 2007; Allebrandt et al. 2013; Parsons et al. 2013; Smith et al. 2013; Nelson et al. 2014). Note that the polymorphisms cluster in the $3^{\prime}$ portion of the gene. Also shown are some of the currently known and annotated $A B C C 9$ gene products - splice variants that encode SUR2 protein. The two most frequently studied SUR2 transcripts are termed SUR2A (Refseq NM_005691.3, for which a 
$3^{\prime}$ untranslated region (3'UTR) has not been annotated) and SUR2B (Refseq NM_020297.3). These two splice variants are produced by differential inclusion and exclusion of Exon38 and Exon39 in the annotated $A B C C 9$ gene. 


\section{rs704180 as eQTL for ABCC9/SUR2: \\ "SNPExp" results (lymphoblastoid cells with DNA from 269 humans)}

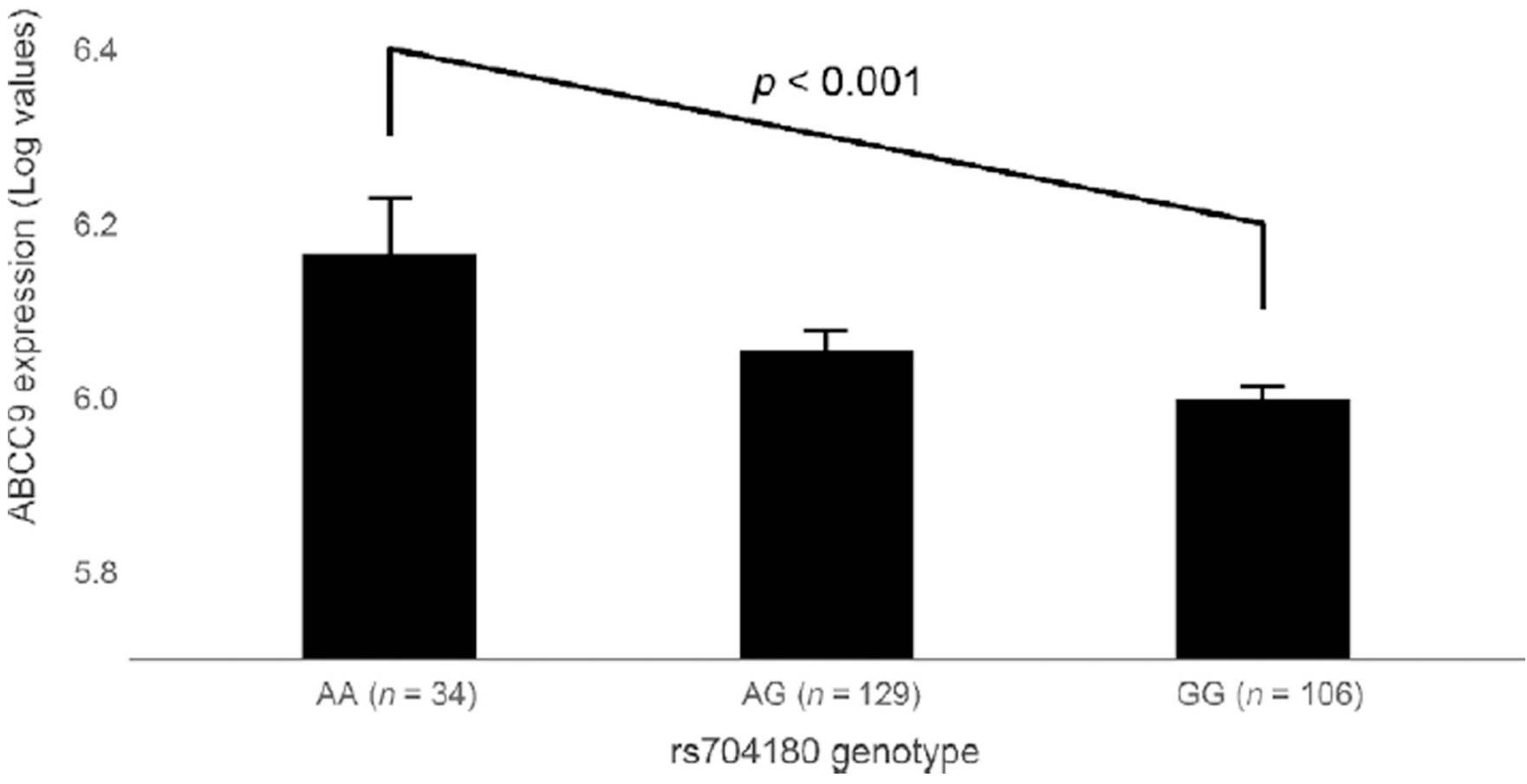

Fig. 2.

Data analyses using the 'SNPExp' website (see Table 1) showing that in transformed lymphoblastoid cells $(n=269)$, the rs704180 risk allele (A_A) correlates with increased expression of the ABCC9 gene product, SUR2 mRNA, indicating that rs704180, which is a risk allele for hippocampal sclerosis of aging, is a cis (local) expression quantitative trail locus (eQTL). 


\section{rs704180 as eQTL for ABCC9/SUR2: "GTEx" results (human brain; $n=34$ )}

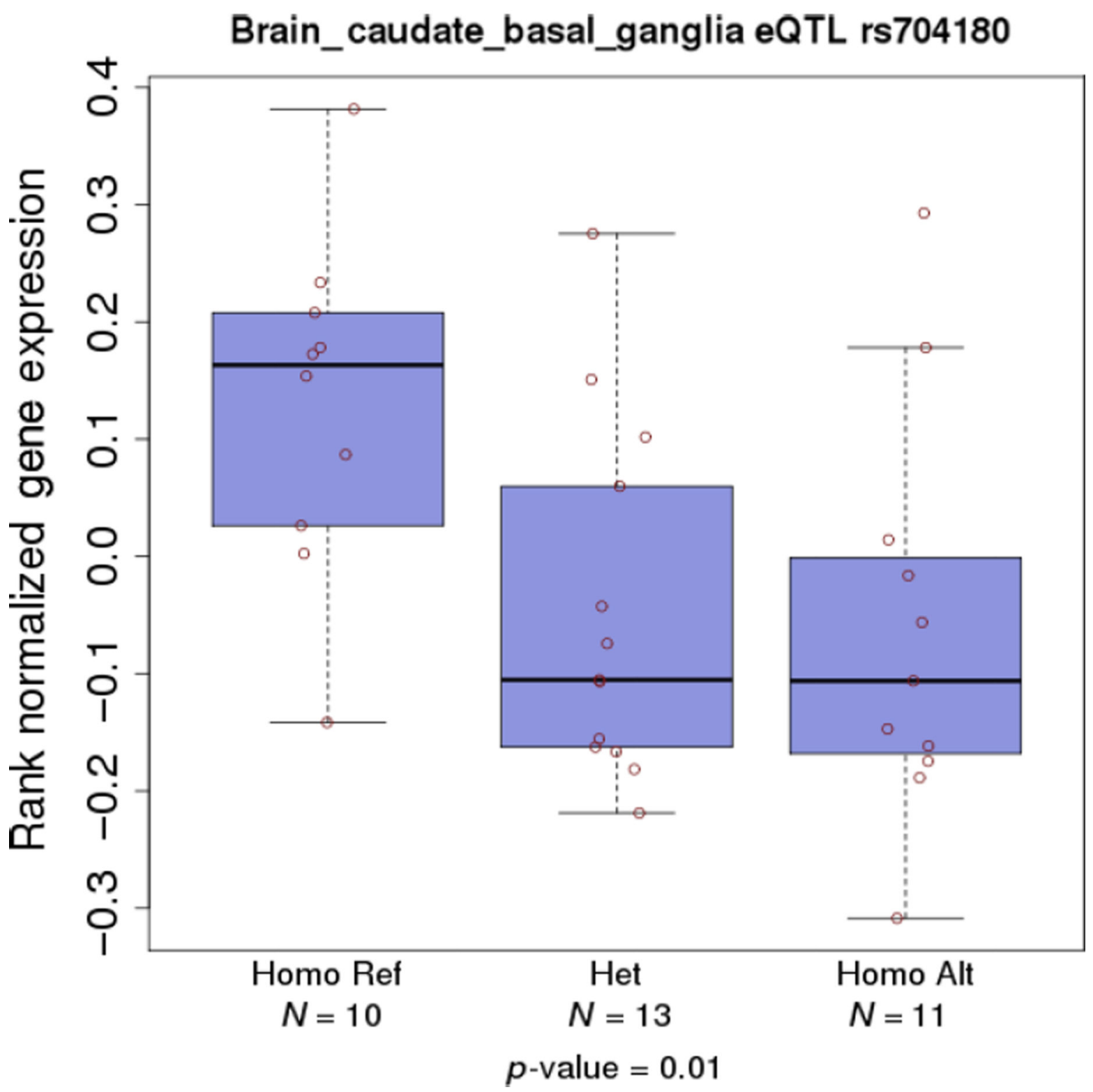

Fig. 3.

Data analyses using the 'GTEx' website (see Table 1) evaluating the human brain area from that database ('caudate and basal ganglia') with the most samples ( $n=34$ total). These analyses again indicate that rs704180 is an eQTL. Note that in these data the Ref allele correlates with increased expression for $A B C C 9(p=0.01)$ but the identification of the allele (A vs. G) is not specified. 
(a)

\section{(10 human brain areas from 133 subjects):}

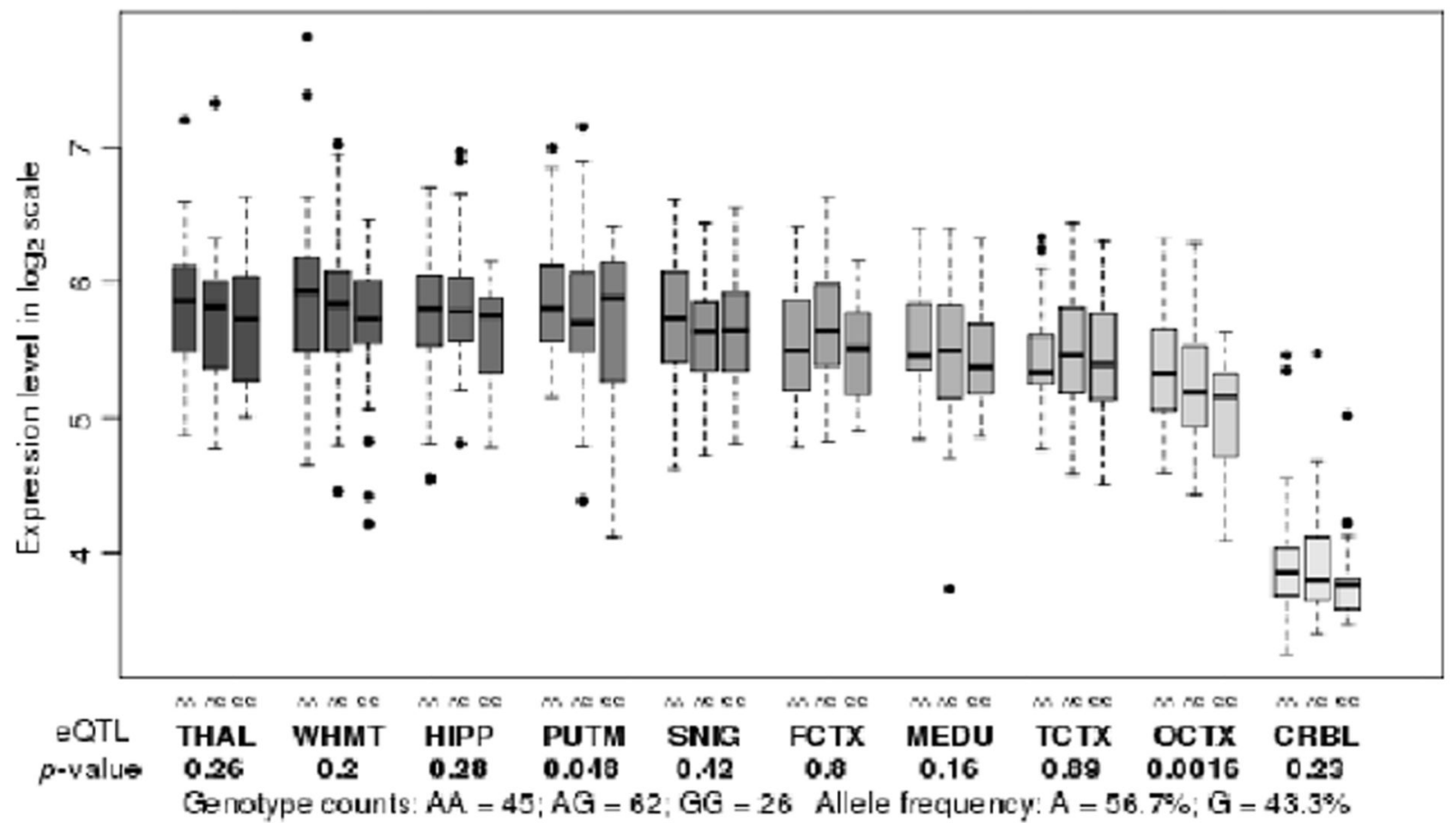

SorseBRAINEAC

\begin{tabular}{|c|c|c|c|c|c|c|c|c|c|c|c|}
\hline \multirow[t]{2}{*}{ (b) } & \multicolumn{10}{|c|}{$\begin{array}{l}\text { Results from "BRAINEAC" data: } p \text { value for association between SNP status and } \\
\text { ABCC9 transcript for cerebellum (CRBL), frontal cortex (FCTX), hippocampus (HIPP), } \\
\text { medulla (MEDU), occipital cortex (OCTX), putamen (PUTM). substantia nigra (SNIG). } \\
\text { temporal cortex (TCTX), thalamus (THAL), and white matter (WHMT) }\end{array}$} & \multirow{2}{*}{$\begin{array}{c}\text { Overall } \\
\text { average } p \\
\text { value factoring } \\
\text { in } \\
\text { "directionality" } \\
\text { aveALL }\end{array}$} \\
\hline & THAL & WHMT & HIPP & PUTM & SNIG & FCTX & MEDU & TCTX & OCTX & CRBL & \\
\hline $\begin{array}{c}\mathbf{1 3 4 4 6 9 1 9} \\
(\text { ABCC9/SUR2) }\end{array}$ & 0.26 & 0.2 & 0.28 & 0.048 & 0.42 & 0.8 & 0.16 & 0.89 & 0.0016 & 0.23 & 0.011 \\
\hline $\begin{array}{l}\text { rs704180 GG } \\
\text { allele trend for } \\
\text { decreased } \\
\text { expression? }\end{array}$ & Yes & Yes & Yes & No & Yes & No & Yes & No & Yes & Yes & \\
\hline
\end{tabular}

Fig. 4.

Data analyses using the'BRAINEAC website (see Table 1) evaluating multiple human brain areas ( $n=133$ cases), focusing on the expression of the $A B C C 9$ gene product, SUR 2 mRNA (Affymetrix transcript ID t3446919). These data provide support for the hypothesis that the rs704180 risk allele (A_A) is correlated with increased expression of SUR2 mRNA in multiple brain areas. The data for each brain area are shown in (a), and digested numbers in (b). The overall $p$ value for the association between the rs704180 genotype and $\mathrm{t} 3446919$ expression is 0.011 . 


\section{"BRAINEAC" results (human brain): individual exons}

\begin{tabular}{|c|c|c|}
\hline $\begin{array}{c}\text { Portion of ABCC9/SUR2 } \\
\text { gene and transcript }\end{array}$ & $\begin{array}{c}\text { Affymetrix } \\
\text { exon ID\# }\end{array}$ & $\begin{array}{c}\text { rs704180 } \\
\boldsymbol{p} \text { value* }\end{array}$ \\
\hline Exon 36 & 3446927 & $\mathbf{0 . 0 0 6 2}$ \\
\hline Exon 37 & 3446926 & 0.0072 \\
\hline Exon 38 (SUR2A) & 3446925 & 0.35 (NS) \\
\hline 5' portion of 3'UTR & 3446923 & 0.0038 \\
\hline 3' portion of 3'UTR & $\mathbf{3 4 4 4 6 9 2 1}$ & 0.85 (NS) \\
\hline
\end{tabular}

\section{ABCC9 $\rightarrow$}

3446922

3446921

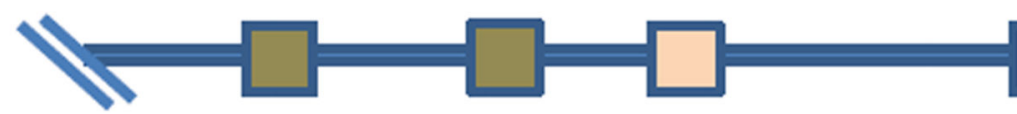

\section{Exon\# 36}

$37 \quad 38$

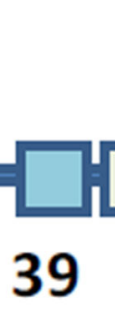

39
3'UTR

*-p value represents the probability that the rs 704180 SNP status is randomly associated with this exon transcript level in all the brain tissue specimens (the "aveALL" parameter, for more details see website http://www.braineac.org)

Fig. 5.

Data analyses using the 'BRAINEAC website (see Table 1) evaluating multiple human brain areas, focusing on the association between rs704180 allele status and expression of individual exons from the SUR2 mRNA (Affymetrix transcript IDs 3446921/3'UTR, 3446923/Exon 38, 3446925/Exon 37, 3446926/Exon 36, and 3446927/Exon 35). Shown are data expressing $p$ values for all the brain areas combined (see Fig. 4). These data provide support for the hypothesis that rs704180 status is associated with different expression of Exons 36, 37, and Exon 39 (SUR2B), and the distal $3^{\prime}$ untranslated region (3'UTR), but not Exon $38(S U R 2 A)$ or the proximal 3'UTR. 
Chr. 12p genomic position using GRCh37/hg19 annotation

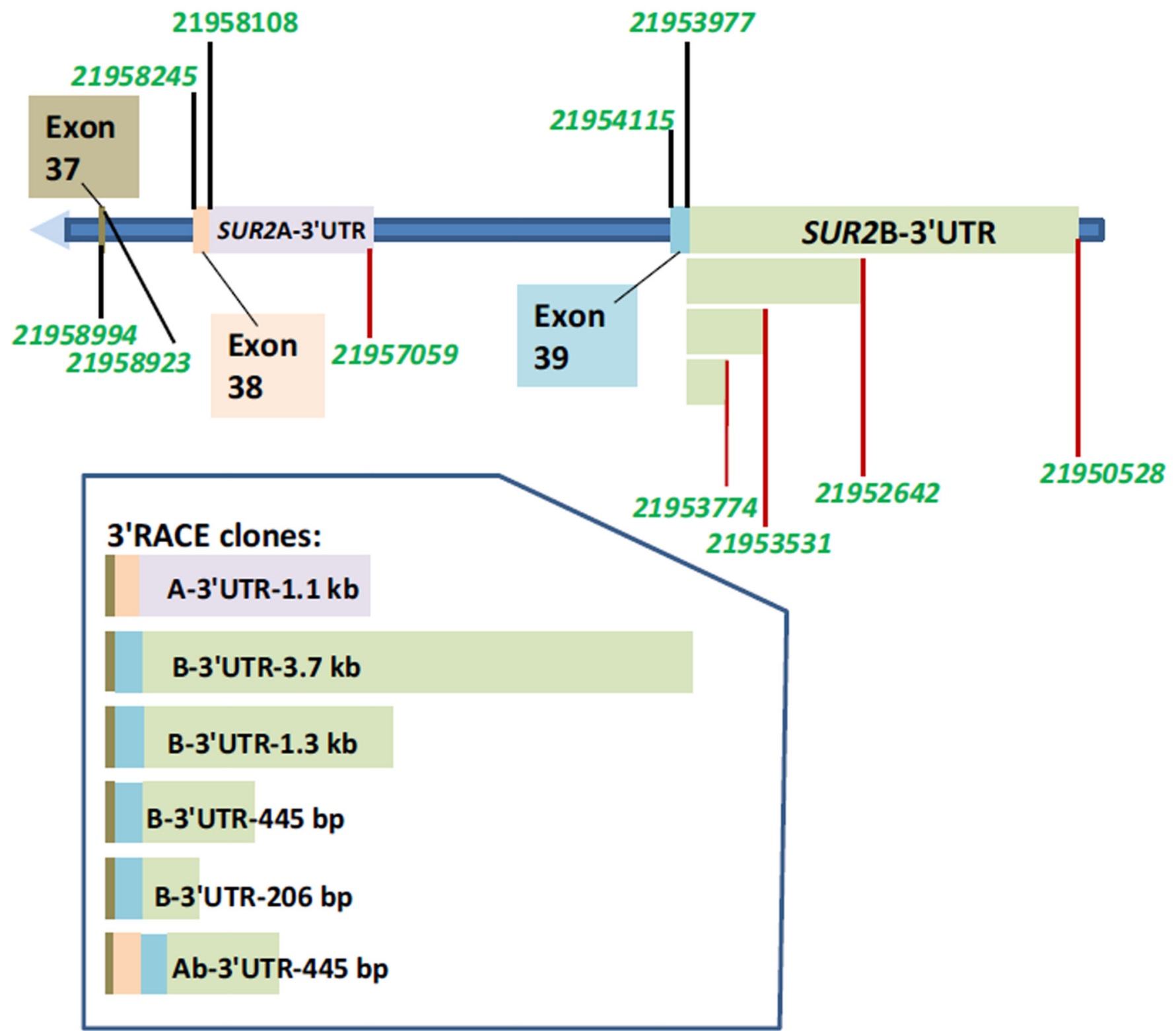

Fig. 6.

3'RACE results with graphic illustration of $3^{\prime}$-end transcripts cloned from human brain. In green are specific genomic locations according to the GRCh37/hg19 annotation. Note that there is a novel $3^{\prime}$ untranslated region (3'UTR) portion that is specific to $S U R 2 A$ transcripts upstream of Exon39 (light purple color). Inset depicts clones that were sequenced. Among these are representative sequences corresponding to $S U R 2$ variants $S U R 2 A, S U R 2 B$, and $S U R 2 A b$. Notably there are alternative lengths of the cloned $3^{\prime}$ UTR of $S U R 2 B$ transcripts identified by $3^{\prime} \mathrm{RACE}$. 


\section{SUR2Ab: nucleotide sequence from 3' RACE}

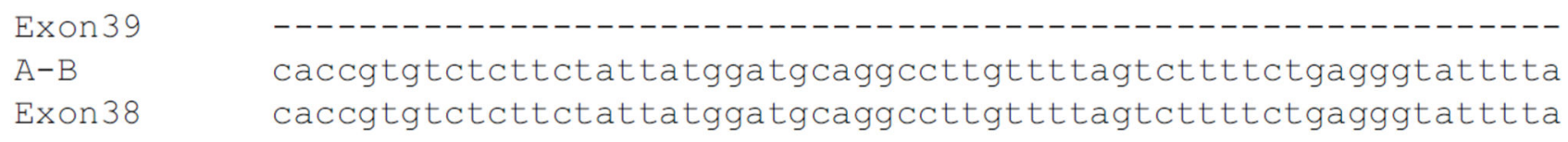

Exon 39

$\mathrm{A}-\mathrm{B}$

gtggagtgtgatactgtcccaaatttgctcgcccacaagaatggcctcttttccactttg

Exon38

gtggagtgtgatactgtcccaaatttgctcgcccacaagaatggcctcttttccactttg

Exon 39

$\mathrm{A}-\mathrm{B}$

Exon 38

gtgatgaccaacaagtagACCATCATGATCTATTGCACCAAGTCTGTCATTCTCCGcatc

$\mathrm{A}-\mathrm{B}$

Exon38

gtgatgaccaacaagtag

Exon 39

aatatgacactccagaaagcctcttggctcaggaaatggagtatttgcttcttttgttc

$\mathrm{A}-\mathrm{B}$

aatatgacactccagaaagcctcttggctcaggaaaatggagtatttgcttcttttgttc

Exon38

Exon39

$\mathrm{A}-\mathrm{B}$

Exon38

gagtacacactattctgacggcagacctggttattgtgatgaagcgaggaaatattttag gagtacacactattctgacggcagacctggttattgtgatgaagcgaggaaatattttag

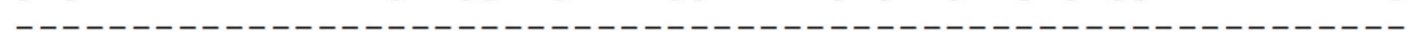

\section{Predicted amino acid sequences: SUR2A, SUR2B, SUR2Ab}

SUR2A

SUR2Ab

SUR2B

\begin{abstract}
HRVSS IMDAGLVLVFSEGILVECDTVPNLLAHKNGLFSTLVMTNK* HRVSS IMDAGLVLVFSEGILVECDTVPNLLAHKNGLFSTLVMTNK* HRVHTILTADLVIVMKRGNILEYDTPESLLAQENGVFASFVRADM*
\end{abstract}

Fig. 7.

A transcript that we term SUR2Ab is expressed in multiple human tissues and here we present the nucleotide sequence (top) and predicted amino acid sequence (bottom) of this transcript. Note that the transcript includes both ABCC9/SUR2 Exon38 (like SUR2A) and Exon39 (like $S U R 2 B$ ) but the translated product would stop before the Exon39 so the mature polypeptide would be identical to SUR2A despite completely different $3^{\prime}$ untranslated region ( $\left.3^{\prime} \mathrm{UTR}\right)$. This transcript has not been annotated in humans but full-length SUR2Ab has been annotated in mice (Isomoto et al. 1996).

J Neurochem. Author manuscript; available in PMC 2016 September 01. 
(a)

SUR2A

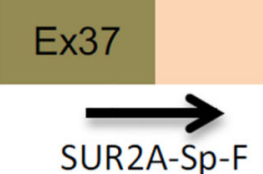

Ex38

aUTR

SUR2A-Sp-F
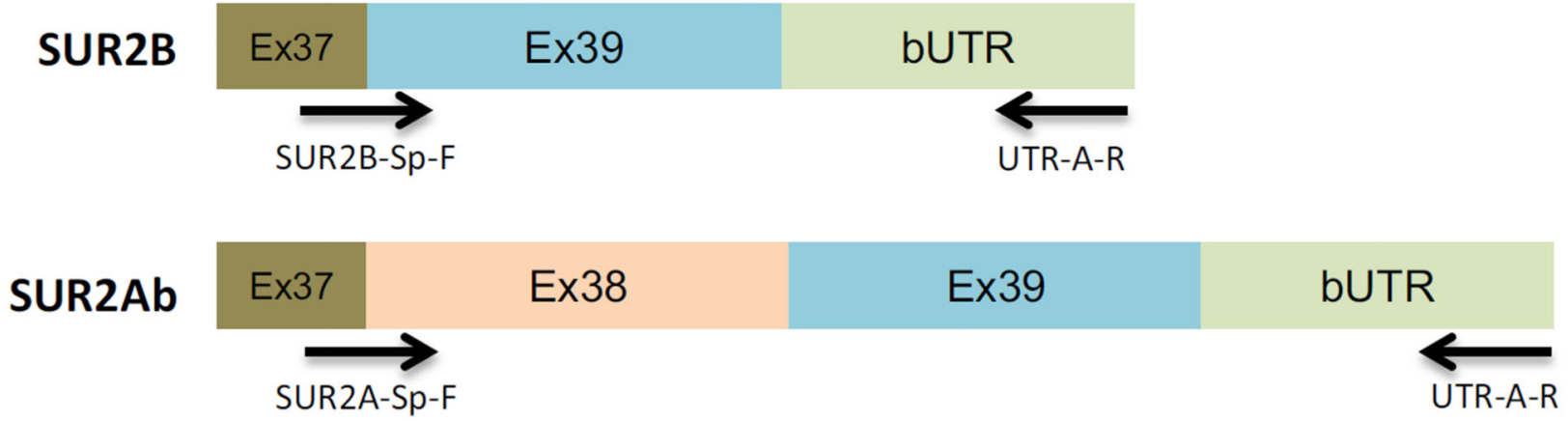

(b)

SUR2A (1203 bp) SUR2B (501 bp) SUR2Ab (679 bp)

总
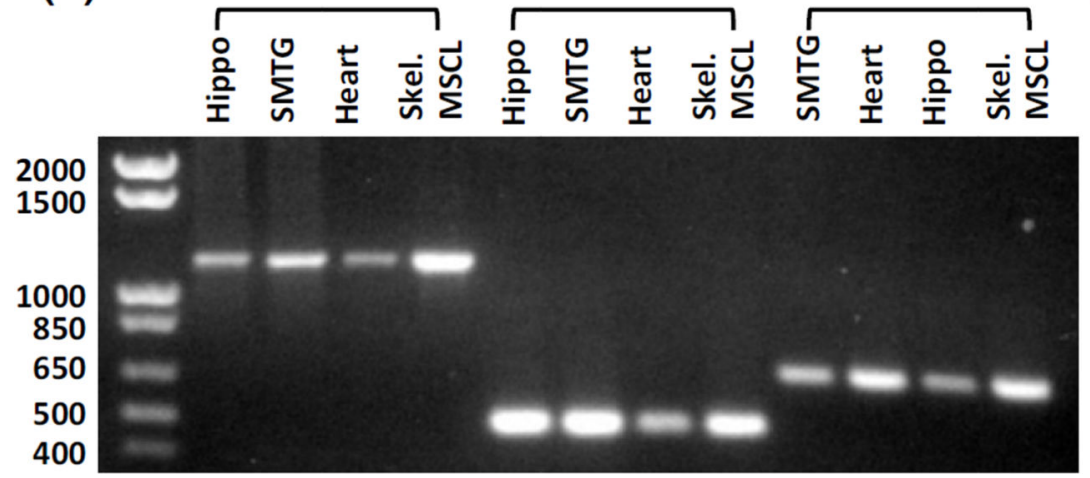

(c) SUR2A SUR2B SUR2Ab

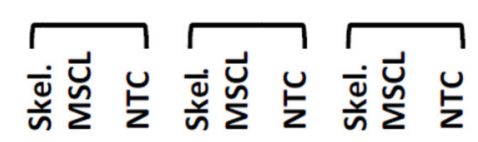

Fig. 8.

PCR to test for the presence of $S U R 2 A, S U R 2 B$, and $S U R 2 A b$ transcripts in human tissues. Primers were developed which span exon junctions to enable transcript subtype-specific PCR (a). Representative PCR results (agarose gel stained with SYBR green stain; b) from human hippocampus (Hippo; in brain), superior and middle temporal gyrus (SMTG; in brain), heart, and skeletal muscle. Panel (c) demonstrates that water only (non-template) controls (NTC) are negative for PCR-amplified DNA. 
(a) Primer location for qPCR

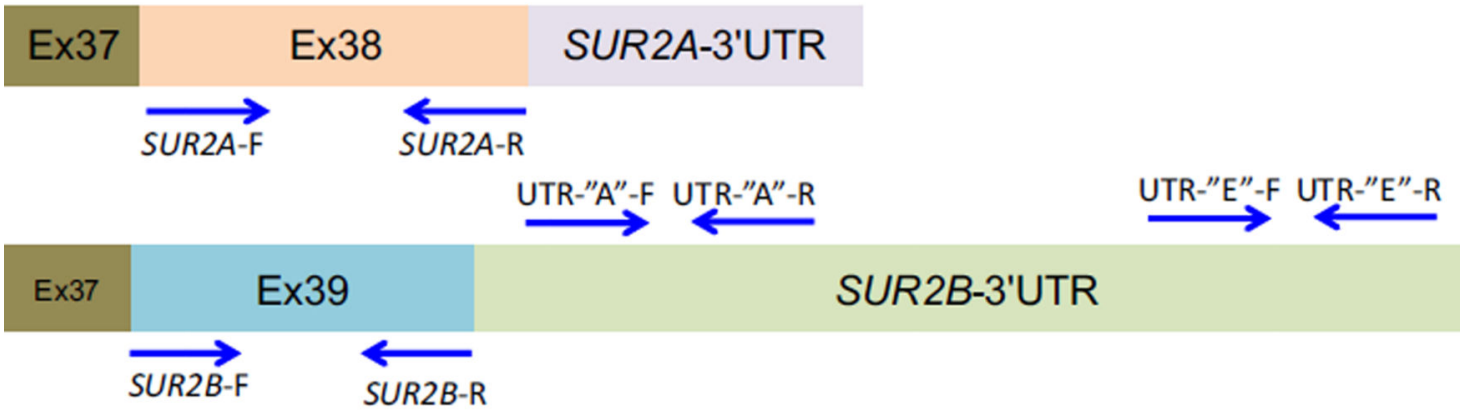

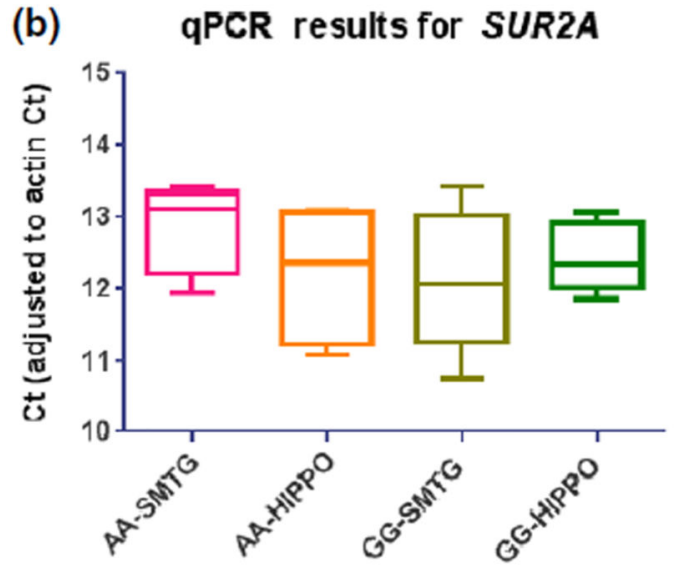

rs704180 genotype-anatomical location

(d) qPCR results for 5' portion of 3'UTR

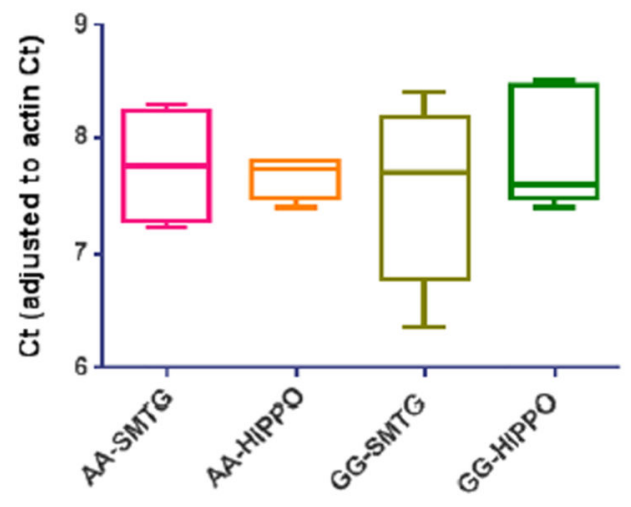

rs704180 genotype-anatomical location

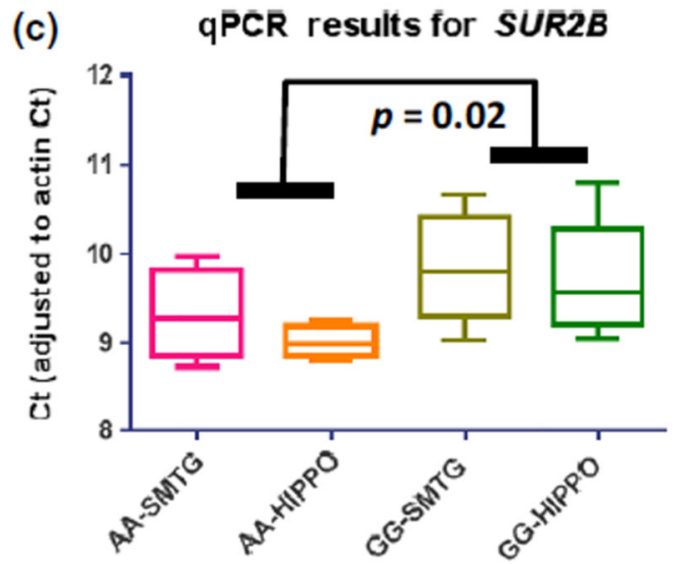

rs704180 genotype-anatomical location

(e) qPCR results for 3' portion of 3'UTR

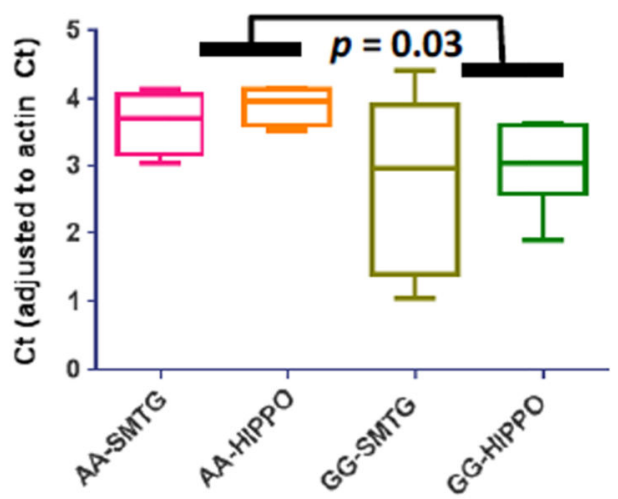

rs704180 genotype-anatomical location

Fig. 9.

Quantitative PCR (qPCR) from human brain tissue samples (see Table S1 for primer sequences), (a) Primers were developed for qPCR to demonstrate amplicons related to Exon38 (SUR2A), Exon39 (SUR2B), and regions of SUR2 $3^{\prime}$ untranslated region (3'UTR) as shown. The results of qPCR experiments are shown in (b-e). Note that $\mathrm{Ct}$ is lower (expression higher) for $S U R 2 B$ in cases with the rs704180 risk genotype (AA) in comparison to cases with GG rs704180 genotype. There also is a lower level of distal 3'UTR portion detected in the cases with the risk genotype. 
Human ABCC9 3' UTR (full-length, NM_020297.3)

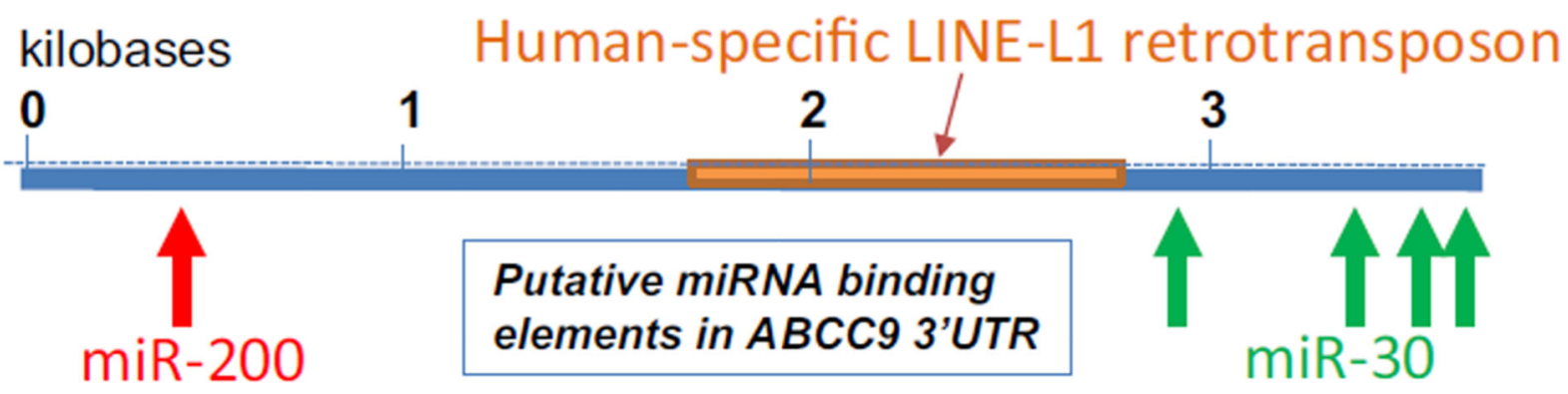
Annotated ABCC9 mRNA sequences evaluated:
Human ABCC9: NM_020297.3 (8325 bp full length)
Mouse ABCC9: XM_006506948.2 (7551 bp full length)
Chicken ABCC9: XM_003640404.2 (6225 bp full length)

MiR-200c:

3' agGUAGUAAUGGGCCGUCAUAAu 5' hsa-miR-200c (3p)

Human ABCC9 5001:5' agugucaaugaguaguCAGUAUUa 3'

Mouse ABCC9 6590:5' cguuagaagaaaguaaUAGUAUUa 3'

Chicken ABCC9 5340:5' cacacuguaguuggcaCAGUAUUg 3'

$\underline{M i R-30 c}$

Human ABCC9 7618:5' aguaaaugucuaauUGUUUACa 3'

Human ABCC9 8052:5' ucgggaccaugucUUGUUUGCc 3'

Human ABCC9 8172:5' c cuuuucuauguugUGUUUAU u 3'

Human ABCC9 8235:5' cucuacaauaaaugUGUUUAUu 3'

Mouse ABCC9 7463:5' uuaugucaccuguaUGUUUACa 3'

Mouse ABCC9 7525:5' uaaauuaguccuuuUGUUUACu 3'

Chicken $A B C C 9 \quad 6199: 5$ ' aaaaauaaagcagaUGUUUACa 3'

Fig. 10.

There are evolutionary conserved putative miRNA target recognition elements in the $3^{\prime}$ untranslated region ( $3^{\prime} \mathrm{UTR}$ ) of $A B C C 9$. The location of these sequences is shown for human (NM_020297.3), mouse (XM_006506948.2), and chicken (XM_003640404.2) ABCC9 transcripts. For each of these species, the miR-200 paralog miRNAs are predicted to bind the $5^{\prime}$ part of the $3^{\prime} \mathrm{UTR}$, whereas the miR-30 paralogs are predicted to bind the $3^{\prime} \mathrm{UTR}$ near the distal portion of the 'full-length' $3^{\prime} \mathrm{UTR}$. Note that the $3^{\prime} \mathrm{UTR}$ of humans is over $3 \mathrm{~kb}$ in 
length and contains a human-specific LINE-LI retrotransposon, the functional significance of which remains unknown. 
(a)

Long

3'UTR

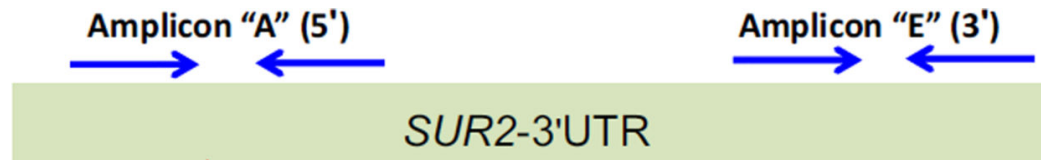

Short

3'UTR

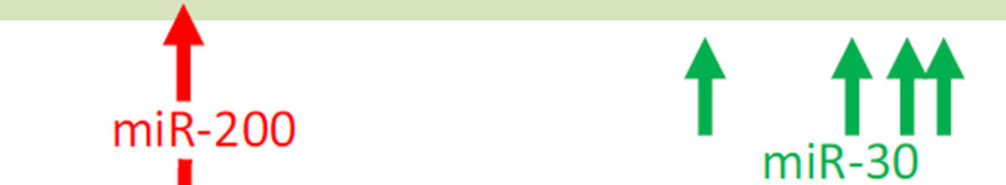

(b) Transfect $\mathrm{H} 4$ cells

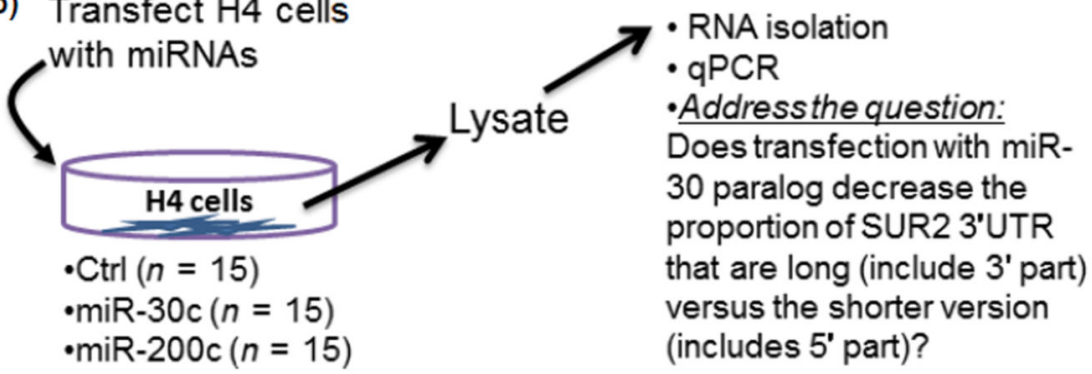

Fold-change by qPCR: level of

(c) amplicon " $A$ " (5') relative to amplicon " $E$ " (3')

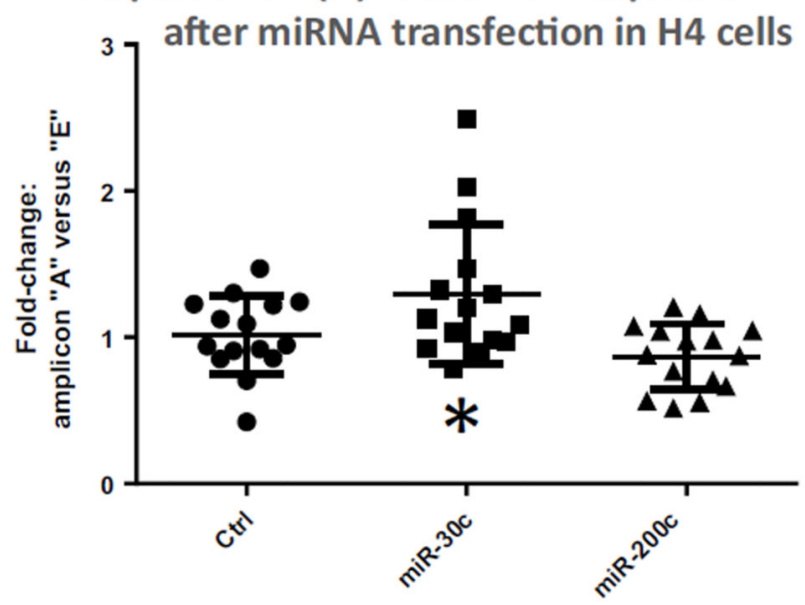

Transfected miRNAs,

$n=15$ biologic replicates per condition

Fig. 11.

An experiment on cultured $\mathrm{H} 4$ cells to test the hypothesis that miRNAs may help to explain the differing apparent stability of mRNAs with the longer, versus shorter, $3^{\prime}$ untranslated region ( $3^{\prime}$ UTR) sequence. The experiment involved miRNA transfections followed by qPCR assessment of amplicons related to the $5^{\prime}$ end of the $3^{\prime}$ UTR (amplicon 'A') versus an amplicon related to the $3^{\prime}$ end of the $3^{\prime}$ UTR (amplicon 'E'). Primer sequences are provided in Table S1. The dispositions of the amplicons and the putative miRNA recognition sequences on the $3^{\prime}$ UTR are shown (a). The overall experiment is described schematically in 
(b). Following transfections with miRNAs (100 nm miRNAs, for $48 \mathrm{~h}, 15$ biologic replicates per condition), cells were harvested and the RNA isolated followed by qPCR for Amplicons A and E. (c) Following transfection with miR-30c, there was relative increase in the proportion of SUR2 transcripts that harbor Amplicon 'A' relative to Amplicon 'E' (* $p<$ 0.03 using 1-tailed Student's $t$-test), normalized to the averaged value of the control miRNA transfections. These data are compatible with the hypothesis that binding by miR-30c is one potential mechanism for SUR2 transcripts with the longer 3'UTR being less stable. 


\section{Table 1}

List of datasets and web servers used for this study to evaluate rs704180 as an eQTL

\begin{tabular}{lll}
\hline $\begin{array}{l}\text { Web server } \\
\text { name and } \\
\text { (citation) }\end{array}$ & $\begin{array}{l}\text { Types of cells } \\
\text { or tissues }\end{array}$ & Weblink \\
\hline $\begin{array}{l}\text { SNPExp } \\
\text { (Holm } \text { et al. 2010) }\end{array}$ & $\begin{array}{l}\text { Transformed } \\
\text { human } \\
\text { lymphobastoid } \\
\text { cells }\end{array}$ & \\
& http://app3.titan.uio.no/biotools/tool.php?app=snpexp \\
GTEx (The GTEx Consortium 2013; & $\begin{array}{l}\text { Human tissues } \\
\text { including } \\
\text { boore 2013) }\end{array}$ & http://www.gtexportal.org/home/ \\
& $\begin{array}{l}\text { brain tissue with } \\
\text { largest sample } \\
\text { size: 'Caudate } \\
\text { basal ganglia' }\end{array}$ \\
& $\begin{array}{l}\text { Human brain } \\
\text { tissue } \\
\text { from multiple } \\
\text { areas }\end{array}$ \\
& http://www.braineac.org/ \\
BRAINEAC & \\
(Ramasamy et al. 2014) &
\end{tabular}




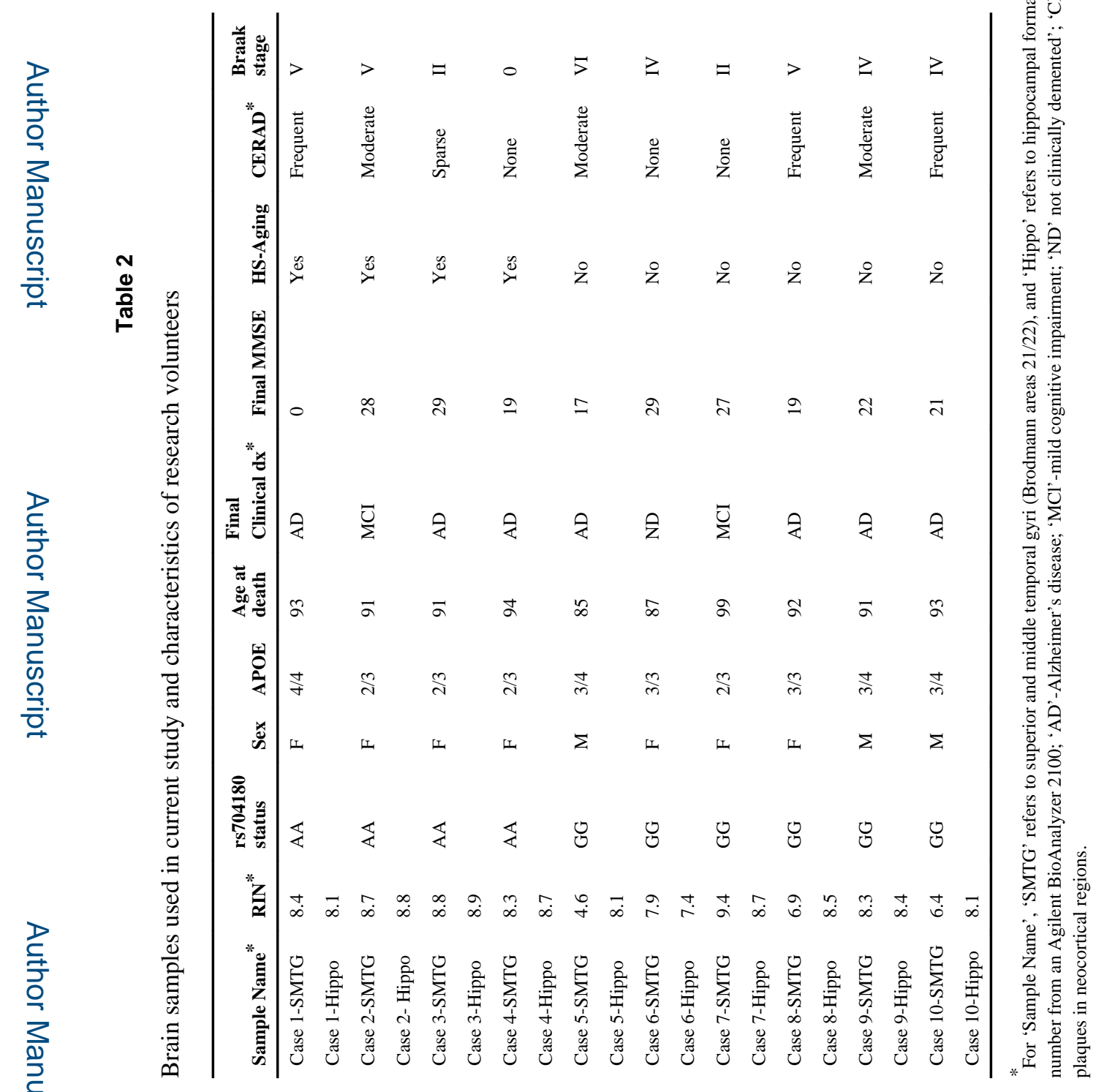

J Neurochem. Author manuscript; available in PMC 2016 September 01. 